Pontifícia Universidade CATÓLICA do RIO de JANEIRO

\title{
A importância da Gestão do Conhecimento nas organizações com perda de pessoal.
}

\section{Beatriz Góes Lacerda}

Trabalho de Conclusão de Curso

CENTRO DE CIÊNCIAS SOCIAIS - CCS

DEPARTAMENTO DE ADMINISTRAÇÃO

Graduação em Administração de Empresas 
Beatriz Góes Lacerda

\section{A importância da Gestão do Conhecimento nas organizações com perda de pessoal.}

Trabalho de Conclusão de Curso

Trabalho de Conclusão de Curso, apresentado ao programa de graduação em Administração da PUC-Rio como requisito parcial para a obtenção do título de graduação em Administração.

Orientador(a) : Marcelo Pineiro

Rio de Janeiro, junho de 2019. 


\section{Agradecimentos}

Agradeço ao meu orientador, professor Marcelo Pineiro, pela orientação e conhecimentos compartilhados comigo durante a realização deste trabalho, e por estar sempre a disposição para tirar minhas dúvidas

À minha família, pelo apoio e por me fornecerem todos os recursos necessários para minha formação acadêmica, profissional e pessoal.

Ao meu namorado, Matheus Appel, por todo apoio, companheirismo e parceria ao longo da faculdade, mas em especial nessa reta final do curso de administração.

À todas as pessoas que se disponibilizaram a responder o questionário, que era a base para que este trabalho pudesse ser desenvolvido, sem vocês não conseguiria cumprir esta etapa da minha vida.

À Deus, por ser minha força e por permitir que eu concluísse com sucesso mais essa etapa. 


\section{Resumo}

Lacerda, Beatriz. A importância da Gestão do Conhecimento nas organizações com perda de pessoal. Rio de Janeiro, 2019, 60 p. Trabalho de Conclusão de Curso Departamento de Administração. Pontifícia Universidade Católica do Rio de Janeiro

Este trabalho aborda a gestão do conhecimento nas empresas, gestão essa que é considerável imprescindível para o sucesso e a continuidade competitiva das organizações. A pesquisa visa identificar de que forma a gestão do conhecimento ajuda a minimizar a perda de conhecimento nas organizações onde ocorreram desligamentos de funcionários, analisando um universo de vinte, e uma amostra de quatorze empresas de setores diversos da economia brasileira que aceitaram responder a um questionário.

Palavras-chave

Gestão do Conhecimento, Empresas, Perda do Conhecimento, Vantagem Competitiva. 


\section{Abstract}

The importance of Knowledge Management in organizations with loss of personnel. Rio de Janeiro, 2019. 60 p. Trabalho de Conclusão de Curso - Departamento de Administração. Pontifícia Universidade Católica do Rio de Janeiro.

This study approaches the management of knowledge in companies, a management that is essential for the success and competitive continuity of organizations. The research aims to identify how knowledge management helps to minimize the loss of knowledge in organizations where there were dismissals of employees, analyzing a universe of twenty, and a sample of fourteen companies from different sectors of the Brazilian economy that accepted to respond to a questionnaire.

Keywords

Knowledge Management, Companies, Loss of Knowledge, Competitive advantage. 


\section{Sumário}

$\begin{array}{ll}\text { 1. O Problema } & 01\end{array}$

$\begin{array}{ll}\text { 1.1. Introdução } & 01\end{array}$

1.2. Objetivos do trabalho 03

$\begin{array}{ll}\text { 1.2.1. Objetivo Principal } & 03\end{array}$

1.2.2. Objetivos secundários 03

1.3. Delimitação do Estudo 03

1.4. Justificativa da relevância do estudo 03

2. Referencial Teórico 04

2.1. Gestão do Conhecimento 04

$\begin{array}{ll}\text { 2.2.1. Origem da gestão do conhecimento } & 04\end{array}$

2.1.2. Diferença entre Dado, Informação e Conhecimento 05

2.1.3. Definindo Gestão do Conhecimento 05

2.1.4. Geração do conhecimento numa organização 06

$\begin{array}{ll}\text { 2.1.5. Codificação do conhecimento nas organizações } & 07\end{array}$

2.1.6. Disseminação do conhecimento nas organizações 07

2.1.7. Gestão do conhecimento como vantagem comparativa 08

2.1.8. Áreas atribuídas à Gestão do Conhecimento 08

2.2. Gestão de Pessoas 11

$\begin{array}{ll}\text { 2.2.1. Conceitos de } \mathrm{RH} & 11\end{array}$

2.2.2. Papéis desempenhados pelo $\mathrm{RH} \quad 12$

2.2.2.1. Admissão 12

2.2.2.2. Compensação pessoal 12

2.2.2.3. Desligamento de funcionários e turnover 12

$\begin{array}{ll}\text { 2.3. Crise financeira de } 2014 \times \text { corte de funcionários } & 14\end{array}$ 
3. Método e procedimento de coleta e de análise de dados de estudo

$\begin{array}{ll}\text { 3.1. Metodologia de pesquisa utilizada } & 16\end{array}$

$\begin{array}{ll}\text { 3.2. Procedimento e instrumento de coleta de dados } & 17\end{array}$

$\begin{array}{ll}\text { 3.3. Análise dos dados coletados } & 17\end{array}$

$\begin{array}{ll}\text { 3.4. Limitações do estudo } & 18\end{array}$

4. Apresentação e análise dos dados 19

4.1. Empresas consideradas no estudo 19

4.2. Respostas obtidas e análise $\quad 21$

4.2.1. Qual a área atribuída à Gestão do Conhecimento? 21

4.2.2. Quando a empresa começou a adotar a Gestão do Conhecimento? 22

4.2.3. Empresas enxergam a Gestão do Conhecimento como algo importante para o sucesso da organização no dias de hoje? 23

4.2.4. Quais as vantagens enxergadas na Gestão do conhecimento? 24

4.2.5. Como o conhecimento é gerado e codificado na organização? 26

4.2.6. Como o conhecimento é disseminado nas empresas? 29

4.2.7. Como o conhecimento tático é transformado em explícito na empresa? 31

4.2.8. Ferramentas tecnológicas que facilitam a utilização do conhecimento 32

4.2.9. A empresa realizou corte de funcionários recentemente? 34

4.2.10. Quais critérios nortearam os desligamentos? 35

4.2.11. A empresa considera que ao demitir um funcionário conseguiu manter o conhecimento dele dentro da empresa?

4.2.12. De que forma a Gestão do Conhecimento minimiza a perda do conhecimento?

5. Conclusões e recomendações 42

5.1. Conclusão 42

5.2. Recomendações 44

6. Referências Bibliográficas 45 
Anexo 


\section{Índice de Tabelas}

Tabela 1 - Empresas usadas no estudo

\section{Índice de Gráficos}

Gráfico 1 - Área que tem atribuição de fazer a gestão do conhecimento

Gráfico 2 - Ano de adoção da gestão do conhecimento nas empresas

Gráfico 3 - Gestão do conhecimento é vista como algo importante

Gráfico 4 - Vantagens da gestão do conhecimento citadas

Gráfico 5 - Formas de geração e codificação nas empresas

Gráfico 6 - Formas de disseminação do conhecimento nas empresas

Gráfico 7 - Formas de transformação do conhecimento nas empresas

Gráfico 8 - Ferramentas utilizadas para facilitar a utilização do conhecimento 41

Gráfico 9 - Corte de funcionários

Gráfico 10 - Critérios utilizados para realização de corte de funcionários

Gráfico 11 - Consideração de empresas que conseguiram manter o conhecimento do funcionário demitido

Gráfico 12 - Processos e ferramentas que colaboraram para manter o conhecimento

Gráfico 13 - Soluções para o aperfeiçoamento na gestão de conhecimento para impedir a perda

Gráfico 14 - Formas que a gestão do conhecimento minimiza a perda do conhecimento 


\section{O Problema}

\subsection{Introdução}

Em meados de 2014, o Brasil se encontrou em um momento de profunda crise econômica, sofrendo uma grande virada, uma vez que estava saindo de um boom econômico para um período de recessão.

O que começou como uma crise econômica, acabou se transformando em uma crise econômico-política, isso se deve ao fato de que perto da reeleição da presidente começaram a surgir informações de esquemas de corrupção envolvendo pessoas de extrema importância para o pais, incluindo de presidentes de grandes empresas brasileira, informações estas que foram obtidas em grande operação que ficou conhecida no mundo todo, a Operação Lava Jato.

Com tal cenário de instabilidade, o Brasil foi entrando em uma recessão muito grande. Segundo o Comitê de Datação de Ciclos Econômicos (Codace), recessão tem como definição uma fase cíclica formada pelo declínio na atividade econômica alastrada em diversos setores econômicos.

Os impactos gerados pela crise começaram a atingir além da macroeconomia do país, a vida particular dos brasileiros. Problemas como a elevada inflação, queda do poder aquisitivo da população, alta dos preços, desemprego começaram a fazer parte do dia a dia dessa população, que até então vinha vivendo um momento de expansão, desde 2010.

A população começou então a reagir a esses problemas, de acordo com uma pesquisa feira pela Confederação Nacional da Indústria (CNI) em 2016, 48\% dos entrevistados passaram a usar mais transporte público, 34\% deixaram de ter plano de saúde. $14 \%$ das famílias trocaram seus filhos de escolas privadas para públicas. Os consumidores começaram a substituir produtos por similares mais baratos $(78 \%)$, esperando liquidações para bens mais caros $(80 \%)$ e economizando mais para uma possível necessidade $(78 \%)$.

Além das pessoas físicas, as pessoas jurídicas também foram impactadas negativamente, fazendo com que estas tivessem que se modificar de alguma forma para que fosse possível perdurar por esse período de queda de produção e do faturamento até o fim da crise.

Alguns ajustes que as empresas começaram a realizar foram desde reduzir investimento até corte de funcionários. 
As empresas começaram a buscar formas de reduzir suas despesas, e em épocas de crise como esta, as empresas tendem a tomar uma medida drástica que é a realização de corte de funcionários, na tentativa de ajustar a produção à demanda. Outro fato que justifica tal corte, é que para se manter tais funcionários é necessário um alto custo.

Mas uma vez demitindo os funcionários, estes levam consigo todo o seu conhecimento individual, inclusive investimento em treinamentos e cursos que as empresas podem ter oferecido a eles.

É de extrema importância que na hora da empresa tomar tal decisão, seja feita uma avaliação. Para que não seja feito um desligamento de funcionários que possuem o knowhow, e que logo depois da crise sejam difíceis de serem substituídos.

E é aqui se se encaixa a Gestão do Conhecimento. Esta é uma forma de minimizar uma série de problemas relacionados a perda de conhecimento numa organização, inclusive na hora de um funcionário ir embora.

Para Davenport e Prusak, a gestão do conhecimento pode ser entendida como um conjunto de processos que visa a criação, disseminação e utilização do conhecimento para atingir os objetivos da organização. (DAVENPORT \& PRUSAK,1998)

A Gestão do conhecimento teve seu início com a globalização e com o avanço da internet, que permitiu uma aproximação maior entre nações e empresas, e também a um elevado fluxo de troca de informações, onde mudanças começaram a acontecer rápida e constantemente. Sendo assim, em um mundo de constantes mudanças, com o conhecimento ficando obsoleto mais rapidamente, a grande vantagem competitiva que as organizações detêm são os seus capitais humanos (capital intelectual) e seus talentos.

O capital intelectual dos funcionários é formado por valores e normas individuais e organizacionais, pelas habilidades e atitudes individuais, e suas competências, e é isso que instiga o conhecimento e gera valor nas empresas atualmente para as empresas, e não mais sendo os ativos tangíveis que a empresa detinha como era anteriormente.

Uma vez que a empresa desse funcionário adote uma ferramenta de gestão do conhecimento, fazendo o registro, divulgando e gerando novos conhecimentos, o que antes era apenas um conhecimento individual do funcionário passou a fazer parte da empresa e a contribuir para o seu crescimento, criando uma vantagem competitiva para empresa, preparando ainda mais esta para enfrentar mudanças e incertezas mais rapidamente.

Portanto as pessoas precisam ser tratadas como ativos estratégicos, parte de extrema importância para que o sucesso de uma organização aconteça.

Ao não possuir uma gestão do conhecimento, não fazendo uso de nenhuma ferramenta da mesma, o funcionário da companhia, ao se desligar da empresa carrega consigo todo o seu conhecimento. 
Tendo em vista tudo que foi abordado acima, se faz presente o questionamento: De que forma a gestão do conhecimento ajuda a minimizar a perda do conhecimento nas organizações ao ocorrerem desligamentos de funcionários?

\subsection{Objetivos do trabalho}

\subsubsection{Objetivo Principal}

Sendo assim, o objetivo principal desse trabalho é identificar de que forma a gestão do conhecimento minimiza a perda do conhecimento nas organizações.

\subsubsection{Objetivos secundários}

- Identificar se a prática de gestão do conhecimento nas empresas é presente

- Verificar se as empresas fizeram desligamento de funcionários e o que foi levado em consideração por elas na hora de o fazerem.

- Levantar a perda do conhecimento nas organizações

- Associar a perda de conhecimento com a gestão do conhecimento

- Observar as vantagens que a gestão do conhecimento traz para as empresas.

\subsection{Delimitação do Estudo}

Serão consideradas para este estudo, vinte empresas que aceitaram responder o questionário proposto deste trabalho, e que cumpriam dois pré-requisitos principais: estar localizada no Rio de Janeiro e ser de porte grande.

\subsection{Justificativa e relevância do estudo}

Para a sociedade como um todo o estudo tem relevância pois vai ajudar a identificar e a destacar a importância de uma gestão do conhecimento de uma forma mais simples e de fácil entendimento, e os impactos que esta acarreta nas empresas.

Além disso, academicamente este estudo tem importância, pois seria mais uma fonte de informações para futuros estudantes do tema, uma vez que gestão do conhecimento é um assunto relativamente novo.

E por último, seria uma forma de mostrar e destacar para as empresas os benefícios de uma gestão do conhecimento, como uma vantagem competitiva, e que pode ser o diferencial para sair de períodos como de crise, por exemplo. 


\section{2.. Referencial Teórico}

\subsection{Gestão do Conhecimento}

\subsubsection{Origem da gestão do conhecimento}

Existem diversos argumentos que são utilizados para justificar o surgimento da gestão do conhecimento, dentre eles seria que consultores teriam desenvolvido essa prática visando maior lucratividade, e que seria apenas uma prática de diversas ferramentas de gestão de informação. $O$ fator que desencadeou tal surgimento foram as tendências econômicas e sociais, como a globalização, visão da importância do conhecimento e surgimento da internet, que serviram de facilitadores para a divulgação, transformação e criação do conhecimento.

E foi nesse ambiente de transformação e tecnologias, que surgiu a Sociedade do conhecimento, em meados da década de 90 . Um dos primeiros autores a tratar da Sociedade do conhecimento foi Peter Drucker em suas obras entre os anos de 1964 a 1998. Para Drucker o pilar principal dessa sociedade são os trabalhadores bem qualificados chamados por ele de Trabalhadores do Conhecimento, sendo assim o conhecimento o recurso primordial e diferenciador das organizações, e que serão a minoria na sociedade, por isso o diferencial.

Já para Squirra (2005) a sociedade do conhecimento seria uma compilação entre a configuração e aplicação da informação com as tecnologias da comunicação.

Para Alvin e Heidi Toffler (2000), estamos vivendo a terceira onda de grandes transformações que já aconteceram no mundo. A primeira sendo a propagação da agricultura pelo mundo, a segunda a industrialização e a terceira a economia voltada ao conhecimento e à informação.

Ou seja, podemos observar que a "Era do conhecimento", através da globalização permitiu uma queda das barreiras nacionais e consequentemente movimentação de produtos, serviços, capital e recursos humanos e ideias gerenciais que criam valor econômico, e junto com isso o avanço da tecnologia, que tornaram mais rápida e eficiente as comunicações, transportes, produção, distribuição.

Agora que já sabemos a sua origem, é necessário entender o que é a gestão do conhecimento, e para isso é necessário saber diferenciar três conceitos básicos que a regem, sendo eles: Dado, Informação e Conhecimento. 


\subsubsection{Diferença entre Dado, Informação e Conhecimento}

Não é possível compreender conhecimento e sua gestão sem saber os conceitos e as diferenças entre dado, informação e o conhecimento. É fato que que eles estão relacionados entre si. Sendo eles marcos conceituais e primordiais das formulações, proposições e discussões sobre as organizações do conhecimento e a gestão da informação e conhecimento. (ALVARENGA NETO, 2008,p.17).

Os dados são elementos em sua forma bruta, sem significados, podendo ser definido como conjunto de fatos distintos e objetivos, relacionados a algum evento. São a matériaprima da informação, descrevem apenas parte do que ocorreu, sem fazer interpretações e sem qualquer base capaz de sustentar uma tomada de ação. E, por isso, que não possuírem uma qualidade boa, influenciam informações e decisões a serem desqualificadas também. (DAVENPORT \& PRUSAK,1998)

Já as informações são dados que proporcionam um ponto de vista para interpretação de eventos, passando a dar significado a algo que anteriormente não tinha, visa modelar a pessoa que a recebe fazendo alguma diferença em sua perspectiva. É necessária para extrair e construir o conhecimento. (DAVENPORT \& PRUSAK,1998)

Por fim, o conhecimento é então uma crença produzida pela informação, sendo a informação com um valor agregado, assimilada por um indivíduo e/ou organização e incorporada ao seu saber anterior. Segundo Davenport e Prusak, é uma mistura de experiencias, valores, informações contextuais e insights experimentado, a qual proporciona uma estrutura de avaliação e integração de novas experiencias. (DAVENPORT \& PRUSAK,1998)

E para Nonaka e Takeushi (1997), esse conhecimento pode ser classificado como tácito e explícito. Segundo esses autores eles são estruturas básicas que se complementam e a criação do conhecimento na organização de negócios é advinda da interação entre ambos. O conhecimento tácito é o conhecimento presente na mente humana, e que sua expressão em forma tangível física, seja em documentos, ou em fala é difícil, só podendo ser avaliado por meio da ação. É o conhecimento pessoal relacionado ás experiencias individuais, envolvendo crenças pessoais, emoções, valores, por exemplo. Já o conhecimento explícito é aquele que pode ser expressado em linguagem formal, transmitido com facilidade, sistematizado e comunicado.

\subsubsection{Definindo Gestão do Conhecimento}


Para Davenport e Prusak, a gestão do conhecimento pode ser entendida como um conjunto de processos que visa a criação, disseminação e utilização do conhecimento para atingir os objetivos da organização. (DAVENPORT \& PRUSAK,1998).

Para Oliveira (2006) a gestão do conhecimento é "o processo de obter, gerenciar e compartilhar o conhecimento dentro de uma mesma organização".

\subsubsection{Geração do conhecimento numa organização}

Segundo Davenport e Prusak (2003), organizações saudáveis geram e usam o conhecimento. E conforme vai havendo interação entre elas e seus ambientes, elas acabam absorvendo informações, transformando-as em conhecimento e passam a agir com base numa combinação desse conhecimento com suas experencias, valores e regras internas.

Existem formas de gerar o conhecimento conscientemente e intencionalmente, que são as atividades e iniciativas que as empresas adotam para aumentar seu estoque de conhecimento corporativo.

Davenport e Prusak (2003), dizem que são formas de geração do conhecimento, tais atividades:

- Aquisição: O conhecimento adquirido por uma organização e também o conhecimento que ela desenvolve envolvem a geração do conhecimento. Esse conhecimento adquirido não necessariamente é um conhecimento recém-criado, podendo ser apenas uma novidade para aquela organização.

Segundo eles, a maneira mais eficaz e rápida de gerar o conhecimento é através da compra, ou seja, adquirir uma organização ou contratar indivíduos que o possuam.

- Aluguel: O conhecimento adquirido pode ser alugado ou financiado. Esse aluguel do conhecimento, é literalmente alugar uma fonte de conhecimento. O aluguel do conhecimento envolver, de alguma maneira, uma transferência do conhecimento, por mais que o aluguel seja por um tempo determinado, parte daquele conhecimento tende a permanecer na empresa. O apoio financeiro que uma empresa oferece à uma pesquisa universitária ou institucional em troca do direito de prioridade no uso comercial de resultados promissores é um exemplo do conhecimento adquirido através do financiamento.

- Recursos dirigidos: É formar unidades e grupos com o objetivo de gerar conhecimento. Por exemplo, o departamento de pesquisa e desenvolvimento numa empresa, onde ele possui a finalidade de criar e desenvolver um novo conhecimento, novas formas de desempenharem as coisas.

- Fusão: A geração do conhecimento através da fusão traz à tona uma complexidade e conflito para criar uma nova sinergia. Isso porque, ela reúne pessoas com diferentes 
perspectivas para trabalhar em um projeto ou problema, fazendo com que elas tenham que chegar a uma conclusão em conjunto.

- Adaptação: Mudanças externas e até mesmo internas, fazem com que as empresas se adaptem. Novos produtos de concorrentes, novas tecnologias e mudanças socais e econômicas incentivam a geração do conhecimento pois, se a empresa não se adaptar às mudanças as chances de ocorrer um fracasso são grandes.

- Rede: O conhecimento pode ser gerado também a partir das redes informais e auto organizadas, que podem acabar, com o tempo, sendo formalizadas. Comunidades possuidoras do conhecimento acabam se aglutinando motivadas por interesses comuns, e geralmente, seus componentes conversam pessoalmente, por telefone e pelo meio eletrônico e groupware para compartilhar o conhecimento e resolver problemas em conjunto. Quando essas redes partilham conhecimento comum suficiente para se comunicar e cooperar, a continuidade de seu contato costuma gerar conhecimento novo dentro da organização.

\subsubsection{Codificação do conhecimento nas organizações}

Para Davenport e Prusak (2003), o objetivo de codificar o conhecimento é apresentá-lo de uma forma mais acessível para as pessoas que dele precisam. A codificação, nada mais é do que a transformação do conhecimento em Código para torná-lo inteligível e o mais claro, portátil e organizado possível. Nas empresas a codificação converte o conhecimento para formatos acessíveis e aplicáveis, onde gerentes e usuários daquele conhecimento podem categorizá-lo, descrevê-lo, mapeá-lo, modelá-lo, estimulá-lo e inseri-lo em regras e receitas.

\subsubsection{Disseminação do conhecimento nas organizações}

Segundo Davenport e Prusak (2003), a transferência de conhecimento nas organizações acontecesse, independentemente se ele é gerenciado ou não. A transferência do conhecimento vai desde as coisas mais simples, como por exemplo um funcionário pergunta a um colega da sala ao lado como ele poderia elaborar um orçamento que lhe foi pedido, nessa hora ele está solicitando uma transferência de conhecimento.

A disseminação do conhecimento consiste na prática da transferência do conhecimento, podendo ser pela contratação de pessoas, pelas conversas informais e não programadas, ou por reuniões e ações estruturadas que possibilitam a mobilidade do conhecimento pela organização. 
De acordo com uma pesquisa realizada pela EConsulting Corp com grandes empresas no Brasil, apresentada na HSM (2004, p.42), as ferramentas mais utilizadas na hora de realizarem a transferência do conhecimento são: E-mails (84,2\%), Debates (46,3\%), Listas de discussões (29,0\%), Chats (22,5\%), Mensagens Instantâneas (18,8\%), Multiplicadores de conhecimento $(16,4 \%)$, e Outras $(14,5 \%)$.

\subsubsection{Gestão do conhecimento como Vantagem Competitiva}

A nova era do conhecimento, caracterizada por organizações flexíveis, pela rápida obsolescência dos conhecimentos, com o desenvolvimento de uma força de trabalho de classe mundial, fez despertar a necessidade da empresa em observar a gestão dos seus ativos intangíveis, - capital intelectual, como uma vantagem competitiva.

Para Chiavenato, "o capital intelectual é tudo o que uma pessoa sabe. Em termos organizacionais, o maior patrimônio de uma organização é algo que entra e sai pelas suas portas todos os dias, ou seja, são os conhecimentos que as pessoas trazem em suas mentes - sobre produtos, serviços, clientes, processos, técnicas, etc. Este capital intelectual é algo que não se vê, que não é físico, e nem ocupa lugar, não é contabilizado pelas tradicionais partidas dobradas nem equacionando em número quantificáveis, mas que está transformando rapidamente o mundo dos negócios. Isso significa que ter as pessoas certas e saber aplicá-las, mantê-las e monitorá-las é vital para as organizações de hoje e de amanhã." (CHIAVENATO,1999, p.419).

Dessler (2003,p.14) define vantagem competitiva como qualquer fator que permite uma empresa diferenciar seus produtos ou serviços dos seus concorrentes, a fim de aumentar sua participação no mercado. E para alcançar essa vantagem competitiva, as organizações precisam então deter algo que seus concorrentes não possuem, mas desejam ter.

Para Milkovich e Boudreau, "uma vantagem competitiva sustentável ocorre quando uma empresa implementa uma estratégia de criação de valor que não esteja implementada pelos concorrentes de forma real ou potencial, e quando outra organização é incapaz de copiar os benefícios dessa vantagem".(MILKOVICH e BOUDREAU,2000,p.136)

Nessa Sociedade do conhecimento, o que gerava valor para empresa deixou de ser os ativos tangíveis, e passou a ser os ativos intangíveis, que são as pessoas, o capital humano e seus talentos.

Sendo assim, em um mundo de constantes mudanças, com uma rápida obsolescência do conhecimento, a grande vantagem competitiva que as organizações detêm são o capital humano e os seus talentos, formados por valores e normas individuais e organizacionais, pelas competências, habilidades e atitudes de cada pessoa, é isso que 
estimula a geração de conhecimentos e geração de valor nas empresas. Portanto, as pessoas devem ser tratadas como ativos estratégicos. (TERRA,2000).

Para Milkovich e Boudreau, a empresa que possui um diferencial que não seja de fácil imitação pelos concorrentes é que possui vantagem competitiva, e atualmente, o que traz essa vantagem é o conhecimento, ou seja, capacidade que as pessoas têm de criar e modificar os processos. Assim, as principais exigências organizacionais é capturar e reter melhor o capital humano. (MILKOVICH E BOUDREAU, 2000)

Segundo Cavalcanti (2001), com a globalização, e a proximidade entre as nações e empresas, a competitividade passou a ser um tema principal. A necessidade de se impor em um mercado competitivo e com mudanças repentinas fez com que muitas empresas trocassem o trabalho humano pela tecnologia, gerando assim desempregos. O desempenho das pessoas nas organizações e sobre o valor de seus conhecimentos foram alterados, sendo necessário desenvolver uma nova forma de gestão, e uma das maneiras de enfrentar essas mudanças no ambiente organizacional é gerar, obter e aplicar o conhecimento continuamente.

Para Terra (2005) as empresas ainda possuem um pouco de dificuldade, uma vez que parece muito novo, entender a velocidade com que os conhecimentos necessitam ser capturados, gerados, disseminados e armazenados. É necessário fazer a inovação permanentemente, e não simplesmente produzir mais, melhor e barato. A gestão do conhecimento engloba uma gestão de todos os processos e funções da organização que possam impactar tais atividades. Com um ambiente de rápidas mudanças, a vantagem competitiva precisa ser reinventada constantemente.

Para Marras (2005, p.128), "é necessário que as empresas considerem, a importância dos seus ativos intangíveis, como o capital intelectual e as competências profissionais dos trabalhadores."

O capital humano é intangível e não pode ser gerenciado da mesma forma que as empresas gerenciam produtos, cargos e tecnologias. Uma das razões para isso é que são os funcionários que detêm o capital humano, e não a empresa. Ao saírem funcionários valiosos de uma empresa, eles levam consigo seu capital humano, e qualquer investimento que a empresa tenha feito no treinamento e desenvolvimento dessas pessoas fica perdido para ela. (BOHLANDER,2005, p.09)

\subsection{8 Áreas atribuídas à Gestão do Conhecimento}

Para Davenport e Prusak (2003), para que a gestão do conhecimento possa prosperar na organização como um todo, é claro que todos que a compõem precisam ajudar, porém é 
necessário ter algumas funções dedicadas exclusivamente à gestão do conhecimento na empresa.

E que os fatores que mais devem ser levados em consideração ao realizar por onde começar a gestão do conhecimento são a importância da área específica do conhecimento para a empresa e a viabilidade do projeto. E ao escolher qual função/ área será responsável por essa gestão, é imprescindível que essa área responsável esteja coerente com a cultura da empresa. Ou seja, é importante que a área escolhida por desempenhar tal função, seja uma área de extrema relevância para que a realização das atividades da empresa, seja uma área chave. Por exemplo, há empresas que são fortemente baseadas em tecnologia, sendo assim, importante que elas ergam a gestão do conhecimento sobre a base de suas iniciativas e planos de tecnologia. Outras empresas são mais orientadas para finanças e contabilidade, para qualidade ou para programas de mudança organizacional.

Ainda Segundo Davenport e Prusak (2003), qualquer das áreas que sejam escolhidas vai fazer com que a iniciativa de conhecimento decole, porém, para que seja uma prática constante, serão necessários o apoio e os talentos de vários grupos diferentes da empresa.

Dito isso, as áreas que Davenport e Prusak (2003) consideram como áreas responsáveis por começar a gestão do conhecimento são: área de Tecnologia; de qualidade/reengenharia/melhorias práticas; Aprendizado organizacional/Recursos Humanos.

Área de Tecnologia como sendo uma das áreas mais escolhidas pelas empresas para dar o passo à gestão do conhecimento, as empresas instalam o Notes ou uma intranet e depois começam a buscar conteúdos para distribuir com essas ferramentas.

Área de qualidade/reengenharia/melhores práticas, segundo Davenport e Prusak (2003), seria a segunda escolha mais popular para realizar a gestão do conhecimento. Uma vez que os objetivos dos programas de mudanças de processos é compilar e alavancar as melhores práticas ou maneiras efetivas de executar um processo que tenha sido observado na empresa ou fora dela. E essas melhores formas geralmente são armazenadas em repositórios eletrônicos para que sejam compartilhadas por toda a organização e se tornem o núcleo de uma iniciativa da gestão do conhecimento.

Outra forma de começar a adoção da gestão, é pelo Aprendizado Organizacional, que está diretamente relacionado com a área de Recursos Humanos. E que segundo os autores Davenport e Prusak (2003), seria uma ótima ideia, mas, que porem as empresas raramente começam a fazem.

A área de contabilidade também pode servir como uma porta de entrada para a gestão do conhecimento. Segundo os autores, muitas empresas criam sua própria contabilidade interna de capital intelectual e do conhecimento, visto que os sistemas de 
contabilidade são um reflexo muito precário do ativo intangível e intelectual da empresa e ficam insatisfeitas com esse modelo, preferindo desenvolver um próprio.

\subsection{Gestão de Pessoas}

\subsubsection{Conceitos de RH}

De acordo com Chiavenato (1999), entende-se como gestão de pessoas o conjunto de políticas e práticas fundamentais para conduzir os aspectos de posição gerencial relacionados com as pessoas ou recursos humanos, incluindo recrutamento, seleção, treinamento, recompensas e avaliação de desempenho. É uma área muito sensível e importante nas organizações. É contingencial e situacional, uma vez que depende dos aspectos como estrutura, tecnologia, processos internos adotados por cada organização entre outras várias variáveis importantes.

Para Fisher e Fleury (1998), a definição de gestão de pessoas é, assim como pensa Chiavenato, um conjunto de políticas e práticas definidas de uma organização a fim de orientar o comportamento humano e as relações interpessoais no ambiente de trabalho.

Chiavenato (2003) conceitua recursos humanos como sendo uma área interdisciplinar que tem a capacidade de envolver inúmeros conceitos oriundos de várias áreas, por tratar diretamente com indivíduos com personalidades distintas, o que requer de qualquer especialista na área de recursos humanos uma experiência e um bom volume de conhecimento em diferentes áreas.

Ainda Segundo Chiavenato (1990), a área de recursos humanos ou de administração do pessoal é responsável pelo suprimento, seleção, manutenção e desenvolvimento dos recursos humanos dentro da empresa. E essa área tem um papel central em um cenário de mudanças e competitividade, dirigido pela qualidade. Com isso, são os funcionários das empresas e seus recursos humanos que promovem a competitividade (CHIAVENATO,2009).

Para Ivancevich (2008), a gestão de recursos humanos não tem apenas a função de arquivar, organizar e realizar manutenção de registros, ela possui um outro papel, onde identifica problemas de recursos humanos e desenvolve soluções. A gestão de $\mathrm{RH}$ é muito mais estratégica e integrada, e qualquer outra função deve atuar junto para atingir o nível necessário de organização, para competir na esfera local. 


\subsubsection{Papeis desempenhados pelo $\mathrm{RH}$}

Para Silva (2007), departamento pessoal é um órgão da empresa que fica responsável por tarefas e atividades específicas, que vão desde a contratação, pagamentos de salários, transportes, férias, licença médica, $13^{\circ}$ salário, entre outras.

Marras (2005) destaca que as funções mais importantes desse departamento são: admissão de novos empregados; Demissões de empregados; Registro legais em controles diversos; aplicação e manutenção das leis trabalhistas e previdenciárias; folha de pagamento; Normas disciplinares.

O Departamento Pessoal apresenta subdivisões de tarefas, sendo elas: admissão de pessoal, compensação de pessoal e desligamento de pessoal

\subsubsection{Admissão}

O setor de admissão é o responsável por cuidar de todo o processo de integração da pessoa contratada pela empresa, dentro dos critérios administrativos e jurídicos.

\subsubsection{Compensação de pessoal}

O setor de compensação tem por atribuição cuidar de todo processo de controle da jornada de trabalho, elaboração da folha de pagamento, controle de benefícios, concessão de férias, pagamento do $13^{\circ}$ salário, cálculos de tributos e contribuições

\subsubsection{Desligamento de funcionários e turnover}

A função do setor de desligamento é cuidar de todo o processo de desligamento e quitação do contrato de trabalho, estendendo-se na representação da empresa junto aos órgãos oficiais (Delegacia Regional do Trabalho, Sindicato, Justiça do Trabalho, etc.) e cuidar de toda rotina de fiscalização.

Chiavenato (2005) fala que o desligamento dos funcionários da empresa ocorre quando a pessoa deixa de fazer parte do Quadro estrutural humano das organizações. Podendo ser feito por desligamento por iniciativa do funcionário, onde este funcionário decide, por razões pessoais ou profissionais, finalizar a relação de trabalho com a organização ou pode ser o desligamento por iniciativa da organização, a demissão, que ocorre quando a organização opta por desligar o trabalhador, podendo substituí-lo por outro mais adequado às suas necessidades ou não.

Conforme Silva (2001) esses desligamentos de funcionários possuem consequências organizacionais negativas, sendo o custo financeiro o mais representativo. Além desse 
custo, a queda de nível de desempenho é bastante significante, pois o funcionário que deixa a empresa possui experiência e domínio das atividades.

Segundo Marques (2004), os desligamentos trazem diversos tipos de custos, não sendo o custo com substituição o único em questão. Se as pessoas que deixam uma organização apresentam melhor desempenho do que as que ficam, a rotatividade reduz a produtividade da mão de obra remanescente. E esse tipo de fluxo negativo de empregados, tem impactos maiores em trabalhos que são mais complexos, que precisam de mais tempo para serem aprendidos.

Ainda para Marques (2004), a chefia precisa ter conhecimento das consequências que a rotatividade de pessoal pode gerar, uma vez que além de gerar insegurança nas pessoas, ocorre também a perda de know-how, grandes custos de seleção e treinamento de pessoal, perda de produção e imagem. As empresas perdem também investimentos feitos em treinamentos e capacitações com funcionários desligados, e essas informações podem acabar sendo recebidas por organizações concorrentes, onde elementos sigilosos e estratégicos podem ser recebidos.

De acordo com Marras (2005), a rotatividade dentro das organizações também pode ser chamada de turnover e o cálculo da rotatividade gera um índice que pode medir uma parte ou ela toda, este índice é o chamado índice de rotatividade.

Chiavenato (2005) afirma que o índice de rotatividade de pessoal é um fato que interfere diretamente no planejamento de $\mathrm{RH}$, uma vez que provoca fortes alterações. Segundo este autor, a rotatividade de pessoal é a saída de alguns funcionários e a entrada de outros para a substituição no trabalho. E que com isso, as organizações acabam sofrendo um processo negativo, pois acabam perdendo energia e recursos disponíveis.

Para Assis (2005), o turnover é a média dos indicadores de entradas(admissão) e saída (desligamentos), tentando capturar a flutuação do Quadro efetivo da funcionários de um determinado período.

Conforme Chiavenato (2002), esse cálculo do turnover é baseado no volume de entradas e saída de funcionários em relação aos recursos humanos disponíveis na organização, dentro de certo período de tempo e em termos percentuais.

Ainda Segundo Chiavenato (1999), "rotatividade de pessoal não é uma causa, mas o efeito, consequência de certos fenômenos localizados interna ou externamente à organização que condicionam a atitude e o comportamento do pessoal". Ele destaca alguns fatores, tanto internos como externos que podem acabar influenciando a rotatividade. Como fatores internos ele cita a política salarial, oportunidade de crescimento, condições de trabalho, tipo de supervisão, cultura e política organizacional, entre outros. Como fatores externos ele cita oferta de procura do Mercado, conjuntura econômica, oportunidades no Mercado, entre outros. 


\subsection{Crise Financeira de 2014 x Corte de funcionários}

De acordo com o dicionário Houaiss (2010) trata-se de um estado de incerteza ou vacilação, fase crítica de uma situação.

Segundo Ferreira (2004), a palavra crise tem como significado uma "manifestação repentina de ruptura do equilíbrio. Fase difícil, grave, na evolução das coisas, dos acontecimentos, das ideias. Manifestação violenta de um sentimento. Período de instabilidade financeira, política ou social." De acordo com tais definições, pode-se entender crise como uma situação de estabilidade que se transforma rapidamente em uma de instabilidade, sendo ela podendo ser social, pessoal ou financeira.

Segundo Goldsmith e Gonçalves, sendo no âmbito financeiro, essa palavra significa "uma aguda, breve, ultra cíclica deterioração de todos ou da maioria dos indicadores financeiros - taxas de juros de curto prazo, preços de ativos, insolvência comercial ou falência de instituições financeiras". (GOLDSMITH,1969 apud GONÇALVES, 2009,p.7)

O Comitê do Instituto Brasileiro de Economia, da Fundação Getúlio Vargas, chamado Codace, considera que há recessão se é vista uma queda generalizada no nível de atividade econômica, independentemente de haver dois trimestres seguido de PIB negativo. São analisados indicadores como consumo, investimento, nível de emprego, desempenho da construção civil, importações e exportações.

Segundo Luiz Cristiano Leite, em uma entrevista ao jornal Cruzeiro do Sul, o administrador e professor da Escol Superior de Administração, Marketing e Comunicação (Esamc), diz que a crise econômica exige ajustes para empresas de todos os tamanhos, que possuem o objetivo de sobreviver à queda na produção e no faturamento até o fim das turbulências. As medidas para isso vão desde o simbólico "cortar o cafezinho" a reduzir investimentos e enxugar o número de funcionários da empresa. Mas as mudanças devem ser feitas com critério, pois podem prejudicar a volta da produção depois da crise. Conforme ele, não é possível passar da crise sem demitir alguns funcionários, uma vez que alguns deles podem ficar sem função com a queda da produção. $O$ alto custo com quadro funcional é o que acaba fazendo com que os empresários se voltem para as demissões em períodos de retração da economia.

Para o economista Marcos Antônio Andrade, professor da Universidade Presbiteriana Mackenzie, também em uma entrevista para o Jornla Cruzeiro do Sul, em 2014,o corte de funcionários ocorre em função das empresas ajustarem a produção à demanda, pois a empresa precisa manter a capacidade produtiva compatível com a necessidade. Mas que tal medida deve ser tomada cautelosamente, embasada em critérios, uma vez que é preciso 
evitar o desligamento de funcionários que possuem o know-how da empresa, uma vez que são esses que assim que a produção se recuperar, não podem ser substituídos facilmente. 


\section{3.. Método e procedimento de coleta e de análise de dados do estudo}

Esse capítulo visa informar quais foram os passos dados para obter as informações necessárias para a realização deste trabalho. Nele é informado o método de pesquisa que foi utilizado, quais foram as fontes de informação que foram escolhidas para coletar os dados do estudo, qual foi o procedimento e os instrumentos utilizados e de formas de análise dos dados coletados e quais são as limitações do estudo.

\subsection{Metodologia de pesquisa utilizada}

De acordo com Vergara (2007) existem duas formas de se classificar uma pesquisa: quanto aos fins - que podem ser exploratória, descritiva, explicativa, metodológica, aplicada ou intervencionista - e quantos aos meios - que podem ser de campo, de laboratório, telematizada, documental, bibliográfica ou experimental. Sendo assim, essa pesquisa se classifica quanto aos fins como descritiva, por expor características de determinada população, neste caso a de empresas que possuem gestão do conhecimento, podendo estabelecer correlações entre variáveis e definir sua natureza, relacionando essa gestão e a perda do conhecimento (VERGARA,2007). E explicativa, pois, é uma investigação com o objetivo de justificar os motivos, esclarecendo quais fatores da gestão do conhecimento contribuem para a ocorrência de determinado fenômeno, a minimização da perda do conhecimento (VERGARA,2007).

Quanto aos meios essa pesquisa pode ser definida como pesquisa de campo e pesquisa bibliográfica. Pesquisa de campo - que é uma investigação empírica realizada no local onde ocorre ou ocorreu um fenômeno ou que dispõe de elementos para explicá-lo, podendo ser entrevistas, aplicação de questionários, testes e observação participante ou não (VERGARA, 2007), por terem sido coletados dados através de aplicação de questionário. E pesquisa bibliográfica - estudo desenvolvido com base em material publicado em livros, revistas, jornais, redes eletrônicas, ou seja, material acessível ao público em geral, uma vez que houve estudos em livros e artigos sobre gestão do conhecimento, em sua grande maioria, a fim de se obter informações para que pudessem ser possível desenvolver esta pesquisa. 


\subsection{Procedimento e instrumento de coleta de dados}

O procedimento realizado a fim de fazer uma coleta de dados foi um levantamento primário de dados, por meio de um questionário feito às pessoas que trabalham em empresas de médio/grande porte e que possuam gestão do conhecimento. O questionário continha perguntas estruturadas, que foram elaboradas a fim de obter informações que teriam os melhores usos e contribuições para que o trabalho fosse desenvolvido. Sobre questionários, Kotler cita que:

O questionário consiste de um conjunto de questões para serem respondidas por entrevistados. Em função de sua flexibilidade, é o instrumento mais comum para coletar dados primários, precisam ser cuidadosamente desenvolvidos, testados e corrigidos antes de serem administrados em larga escala [...] (KOTLER, 1998, p. 121).

$O$ universo do trabalho foi de vinte empresas - que aceitaram responder 0 questionário mediante anonimato e o compromisso da pesquisadora quanto à confidencialidade das informações obtidas e a amostra de quatorze, visto que algumas empresas que o responderam não se encaixavam nos critérios de delimitação desta pesquisa..

O objetivo do questionário era obter informações necessárias para responder os objetivos secundários do trabalho, para que dessa forma respondesse o principal. Nesse questionário foram feitas perguntas sobre gestão do conhecimento das empresas, se elas a praticam, quais ferramentas que possuem, quais vantagens a gestão do conhecimento traz para empresa na visão de quem está respondendo, se houve perda do conhecimento nas empresas ao demitirem funcionários, etc.

\subsection{Análise dos dados coletados}

Partindo do pressuposto da classificação da pesquisa, método utilizado e os instrumentos de coleta de dados, esses dados obtidos sofreram em sua grande maioria tratamento e análise qualitativa, pois quase não se utiliza de números para análise de suas variáveis, onde o problema da pesquisa é compreendido pela exploração do conceito e fenômeno, visando aprofundar a compreensão e também por ter levado em consideração um número pequeno de amostra, apenas vinte empresas. Porém algumas respostas obtidas - mesmo que poucas - puderam ser analisadas com base em ferramentas quantitativas, como por exemplo comparação em percentual, e em gráficos. Para que pudesse ser feita a análise dos dados coletados, foi utilizado como base para tal os assuntos abordados no referencial teórico desta pesquisa. 
A abordagem qualitativa requer do pesquisador um tratamento de informações mais profundo e complexo, uma vez que são dados que não podem ser mensuráveis, são mais "intangíveis", são abertos a mais de um tipo de interpretação, diferentemente da abordagem quantitativa que é baseada em dados mensuráveis. Minayo define esse tipo de abordagem como: "pesquisa qualitativa é a pesquisa que trabalha com universo de significados, motivos, aspirações, crenças, valores e atitudes, o que corresponde a um espaço mais profundo das relações, dos processos e dos fenômenos que não podem ser reduzidos à operacionalização de variáveis" (MINAYO, 2001).

Já a abordagem quantitativa é diferente da pesquisa qualitativa, uma vez que os resultados da pesquisa quantitativa podem ser quantificados. Como as amostras são em sua maioria grandes e consideradas representativas da população, os resultados são tomados como se constituíssem um retrato real de toda a população alvo da pesquisa. Esta pesquisa se centra na objetividade, ela recorre à linguagem matemática para descrever as causas de um fenômeno, as relações entre variáveis, etc. (FONSECA, 2002, p. 20)

\subsection{Limitações do estudo}

Ao longo do desenvolvimento da pesquisa, durante o processo de desenvolvimento da pesquisa, apareceram algumas dificuldades para a realização da mesma. A primeira limitação do estudo foi na hora da amostra, visto que era um estudo onde dependida completamente que as pessoas respondessem o questionário, ou seja, o processo estava completamente dependente da boa vontade das pessoas em parar suas atividades para ajudar a pesquisadora - que a maioria das pessoas não a conhecia diretamente. Além disso, as pessoas que responderam o questionário, só aceitaram faze-lo mediante ao anonimato da pessoa que respondeu e sobre o nome da empresa em que trabalha e o compromisso da pesquisadora quanto à confidencialidade das informações obtidas.

Com isso, o universo da pesquisa é relativamente pequeno, foram obtidas vinte respostas ao questionário, cada uma sobre uma empresa. Visando alinhar as empresas com a delimitação do estudo que é para empresas que possuem cede ou escritório localizadas no estado do Rio de Janeiro e de porte grande. A amostra do trabalho então é de quatorze empresas, visto que empresas de outros estados também responderam o questionário e empresas de porte pequeno também. Outra delimitação é que por esse número de amostra, talvez as conclusões desse estudo não possam ser generalizadas para todas as empresas, e nem para um segmento de mercado específico, já que foram analisadas respostas de empresas de diversos segmentos. 


\section{4.. Apresentação e análise dos dados}

\subsection{Empresas consideradas no estudo}

Para que se pudesse dar continuidade nesta pesquisa, foi necessário dar "pseudônimos" para o nome das empresas, uma vez que uma das condições básicas para aceitarem responder o questionário proposto foi de sigilo enquanto ao nome da empresa e quanto ao nome do funcionário que se dispôs a respondê-lo. Sendo assim, serão chamadas por letras do alfabeto, e com uma pequena contextualização do setor em que a mesma atua, para que possa ter uma mínima noção de pelo menos em que mercado a mesma está inserida. Das vinte empresas que responderam ao questionário, serão consideradas para análise apenas quatorze, visto que essas eram as que respondiam todos os requisites da delimitação desse estudo.

Na tabela 1, podemos observar a relação das empresas e seus mercados de atuação.

Tabela 1: Empresas usadas no estudo

\begin{tabular}{|c|c|c|}
\hline Empresa & Ramo & Descrição \\
\hline A & Energia & $\begin{array}{r}\text { Empresa que atua na geração, transmissão e } \\
\text { comercialização de energia elétrica }\end{array}$ \\
\hline B & Financeiro & $\begin{array}{r}\text { Empresa que oferece soluções e serviços } \\
\text { financeiros nos segmentos corporativo e de } \\
\text { wealth management }\end{array}$ \\
\hline C & Bebidas & $\begin{array}{r}\text { Um dos maiores produtores de bebidas não } \\
\text { alcoólicas do país. }\end{array}$ \\
\hline D & Energia & $\begin{array}{r}\text { Empresa que faz o desenvolvimento de } \\
\text { atividades vinculadas ao setor de energia, } \\
\text { fazendo exploração, produção e } \\
\text { comercialização de petróleo e seus derivados. }\end{array}$ \\
\hline E & Industrial & $\begin{array}{r}\text { Empresa que investe em pesquisa e } \\
\text { desenvolvimento para criar soluções na área de } \\
\text { vedação industrial e juntas de expansão que } \\
\text { protegem o meio ambiente e pessoas contra } \\
\text { fluídos químicos. Fabrica produtos para controle }\end{array}$ \\
\hline
\end{tabular}




\begin{tabular}{|c|c|c|}
\hline & & de vazamentos de produtos químicos \\
\hline$F$ & Saúde & $\begin{array}{c}\text { Empresa alemã, presente a muitos anos no } \\
\text { país, oferecendo equipamentos, insumos e } \\
\text { serviços de diálise, sendo reconhecida pela } \\
\text { inovação e tecnologia de seus produtos e por } \\
\text { estabelecer os mais altos padrões de qualidade } \\
\text { de tratamento. }\end{array}$ \\
\hline G & Construção & $\begin{array}{l}\text { Uma das maiores empresas de engenharia da } \\
\text { América Latina, atuando há décadas na área de } \\
\text { construção pesada no Brasil e no mundo. }\end{array}$ \\
\hline $\mathrm{H}$ & Energia & $\begin{array}{c}\text { Empresa privada de geração, distribuição, } \\
\text { comercialização e soluções de energia elétrica. }\end{array}$ \\
\hline I & $\begin{array}{c}\text { Bebida } \\
\text { Energética }\end{array}$ & $\begin{array}{l}\text { Empresa austríaca que comercializa bebida } \\
\text { energética. Atuando em mais de } 171 \text { países, } \\
\text { inclusive no Brasil }\end{array}$ \\
\hline$J$ & Energia & $\begin{array}{c}\text { Empresa multinacional, que no Brasil oferece } \\
\text { soluções hidráulicas, componentes elétricos e } \\
\text { sistemas de distribuição de energia, produtos } \\
\text { para motores automotivos e para filtração } \\
\text { industrial, além de sistemas de transmissão } \\
\text { para veículos em geral. }\end{array}$ \\
\hline K & Financeiro & $\begin{array}{c}\text { Empresa pública brasileira que fomenta a } \\
\text { ciência, tecnologia e inovação em empresas, } \\
\text { universidades, institutos tecnológicos e outras } \\
\text { instituições públicas ou privadas, sediadas no } \\
\text { RJ. }\end{array}$ \\
\hline $\mathrm{L}$ & Construção Civil & $\begin{array}{l}\text { Empresa que começou suas atividades fazendo } \\
\text { grandes obras públicas, participando da } \\
\text { construção da nova capital do país. Se } \\
\text { tornando uma das maiores empresas de } \\
\text { construção civil, mas com um foco no } \\
\text { desenvolvimento da cidade do Rio de Janeiro. }\end{array}$ \\
\hline M & Navegação & $\begin{array}{l}\text { Empresa Multinacional, pertencente ao maior } \\
\text { fornecedor mundial de serviços marítimos. É } \\
\text { uma empresa de gerenciamento de navios. }\end{array}$ \\
\hline $\mathrm{N}$ & Financeiro & Empresa que oferece serviços bancários, \\
\hline
\end{tabular}




\begin{tabular}{|c|c|c|}
\hline & $\begin{array}{c}\text { sendo atualmente um dos maiores bancos } \\
\text { privados do Brasil. Sendo uma fusão entre dois } \\
\text { grandes bancos. }\end{array}$ \\
\hline
\end{tabular}

Fonte: Própria autora (2019)

\subsection{Respostas obtidas e análise}

\subsubsection{Qual a área atribuída á gestão do conhecimento?}

Gráfico 1- Área que tem atribuição de fazer a Gestão do Conhecimento

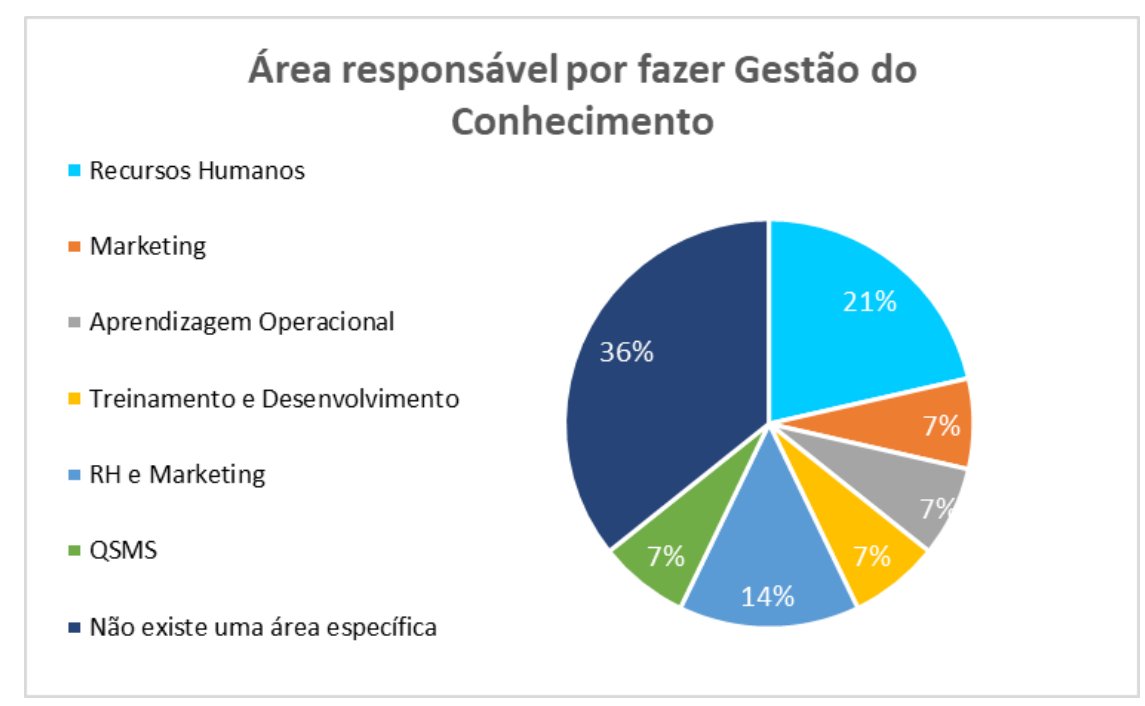

Fonte: Própria Autora (2019)

Podemos observar que a $36 \%$ das empresas, correspondendo a cinco empresas das quatorze que responderam ao questionário, afirmam não possuir uma área responsável pela adoção da gestão do conhecimento.

E isso se relaciona a uma fala de Davenport e Prusak, onde eles dizem que a gestão do conhecimento é baseada em recursos já existentes, com os quais a empresa pode já estar contando, como por exemplo, uma boa gestão de sistemas de informação, uma gestão de mudança organizacional, e boas práticas de gestão dos recursos humanos. E se caso ela possuir uma biblioteca, um sistema de banco de dados textuais e programas educativos, pode-se dizer, então, que a mesma já faz uma adoção da gestão do conhecimento, mesmo que não seja um processo estruturado e sabido por ela.

Sendo assim, como pode ser o caso de várias dessas empresas, acabam sendo pequenos processos de gestão do conhecimento que acontecem dentro de cada área, e por não serem claramente formalizado, acabaram não atribuindo essa gestão a uma área específica. 
Podemos perceber que a área de Recursos Humanos foi a área que mais foi atribuída a gestão do conhecimento. Respostas dadas a essa pergunta como "aprendizagem organizacional", "treinamento e desenvolvimento" e "QSMS - sigla para Qualidade, Saúde, Meio Ambiente e Segurança", estão relacionadas diretamente com a área de recursos humanos, uma vez que estas são funções muitas vezes desempenhadas pelo $\mathrm{RH}$. Considerando isso, pode-se dizer, que área que mais apareceu, com cerca de seis votos foi a de Recursos Humanos. O que mostra pode estar havendo uma mudança por parte das empresas. Isso por que, Davenport e Prusak (2003), disseram que atribuir a gestão do conhecimento à área de Aprendizado Organizacional, era uma ótima ideia, mas, que infelizmente as empresas raramente faziam.

Davenport e Prusak (2003), também citaram que era muito importante para a organização prosperar como um todo e que todas as áreas e todos que a compõem precisam ajudar, além de possuir apenas uma área para gestão do conhecimento. Observar que foi respondido $\mathrm{RH}$ e Marketing, juntos, como áreas atribuídas para essa gestão, mostra que as empresas estão com as áreas compartilhando e se apoiando mutuamente, mesmo que não seja um apoio por enquanto entre todas as áreas, o que vai de acordo com o que os autores disseram.

\subsubsection{Quando a empresa começou a adotar a Gestão do Conhecimento?}

Gráfico 2- Ano de adoção da gestão do conhecimento na empresa

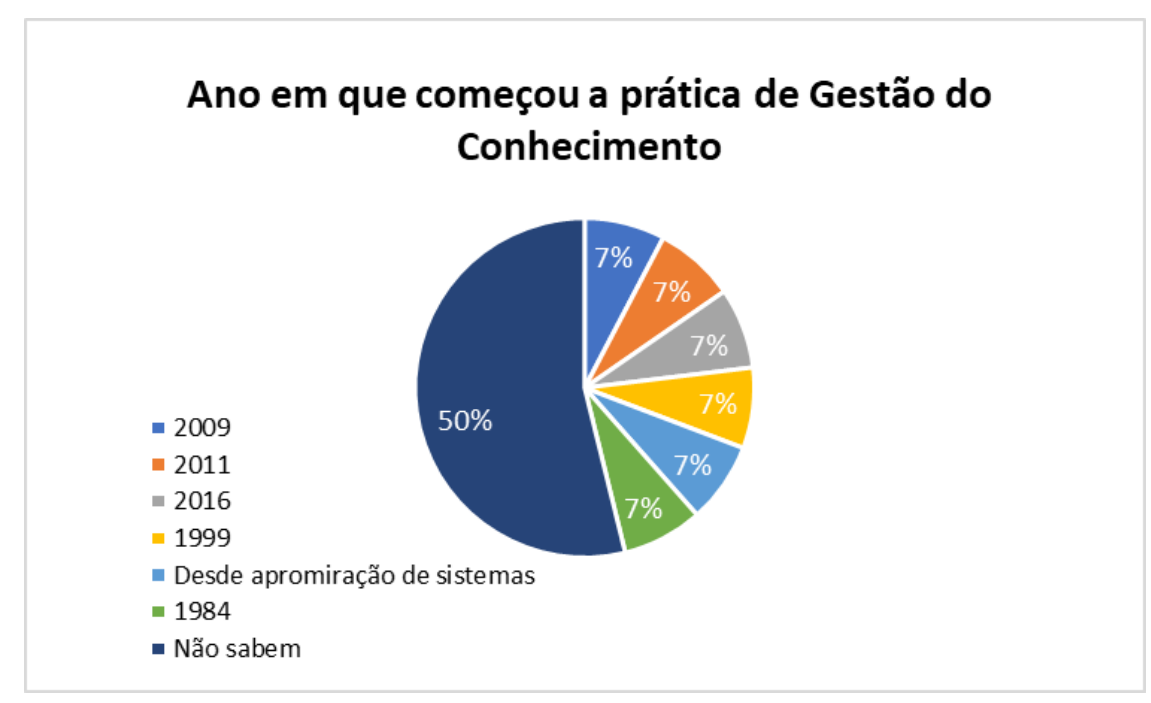

Fonte: Própria Autora (2019)

Como podemos ver no gráfico 2, metade das empresas que responderam o questionário não sabiam afirmar em que ano a prática de gestão de conhecimento começou exatamente. Porém podemos observar com base nas empresas que sabiam as datas, que a adoção da mesma ainda é muito recente, a partir dos anos 2000 , principalmente. Isso pode ser explicado através do surgimento da sociedade do conhecimento - sociedade fruto da 
revolução científica e tecnológica sem precedentes na história (SOUZA, 2010), em meados da década de 90 .

Somente após essas transformações e mudanças, que foi se descobrindo a importância do conhecimento para o sucesso de uma organização e como uma forma de se diferenciar.

Apenas a empresa $\mathrm{M}$, respondeu que a prática de gestão do conhecimento começou a ser adotada nos anos 1984, antes do surgimento da sociedade do conhecimento, o que demostra que provavelmente eles estavam bem atentos a sinais que o ambiente vinha demonstrando, através das constantes e rápidas mudanças que vinham acontecendo no mundo, e perceberam que o conhecimento teria seu valor e portanto, requeria um cuidado mais adequado. Pode ser que o fato da empresa ser multinacional também influenciou nessa visão adiantada sobre a importância do conhecimento, uma vez que no ambiente estrangeiros as coisas tendem acontecer mais rapidamente e no Brasil demoram mais a chegar.

\subsubsection{Empresa enxergar a Gestão do Conhecimento como algo importante para o sucesso da organização nos dias de hoje?}

Gráfico 3 - Gestão do conhecimento é vista como algo importante

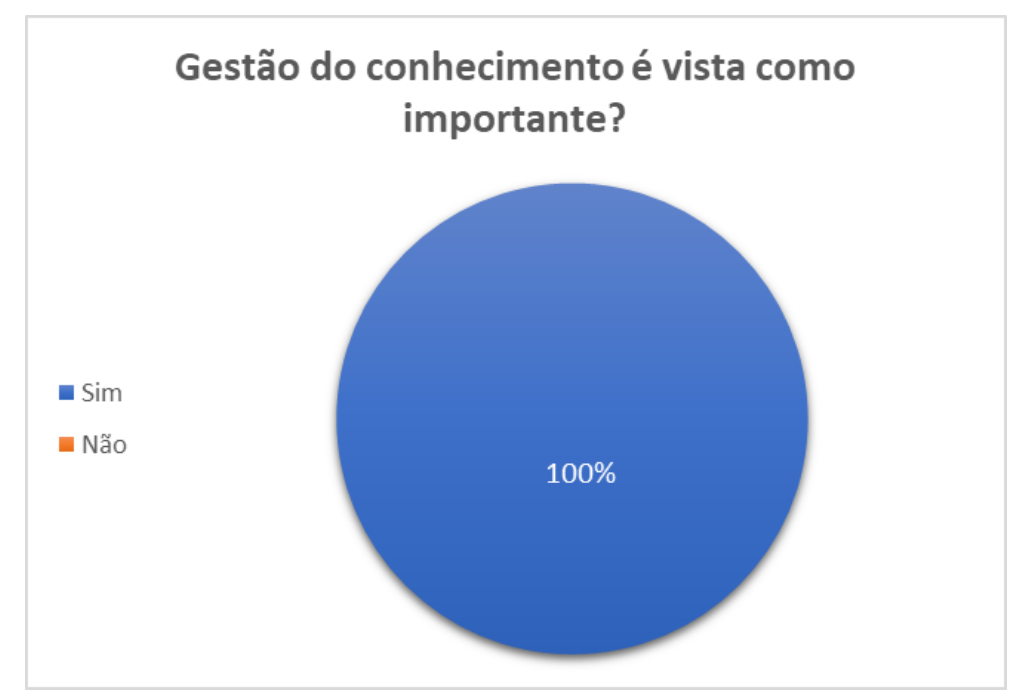

Fonte: Própria Autora (2019)

Quando foi perguntado se elas enxergavam a gestão do conhecimento como algo essencial para o sucesso da organização todas as respostas foram positivas. Uma vez que todas adotam prática de conhecimento, não teria sentido elas adotarem essa prática sem enxergar que fosse importante para o sucesso, e desempenho da organização.

Isso está relacionado com a própria definição de gestão do conhecimento para Davenport e Prusak (1998), que é um conjunto de processos que visa a criação, disseminação e utilização do conhecimento para atingir os objetivos da organização. E que 
para que as organizações atinjam seus objetivos, é necessário a realização de diversas atividades, que só podem ser realizadas por alguém possuir o conhecimento de como a realiza.

Isso está relacionado com o que a gestão do conhecimento é capaz de "trazer" para a empresa. Há diversos fatores que podem levar uma organização a ter sucesso. Devido as condições de mudanças constantes, com uma rápida obsolescência do conhecimento no ambiente em que as empresas e todas as pessoas estão inseridas, a detenção do conhecimento se transforma em uma vantagem competitiva, um diferencial entre as empresas.

Conforme Milkonich e Boudreau, a empresa que possui um diferencial que não seja de fácil imitação pelos concorrentes é que possui vantagem competitiva, e atualmente, o que traz essa vantagem é o conhecimento, ou seja, a capacidade que as pessoas têm de criar e modificar os processos. (MIKONICH E BOUDREAU, 2000).

\subsubsection{Quais vantagens enxergadas na Gestão do Conhecimento:}

Gráfico 4 - Vantagens da Gestão do Conhecimento citadas

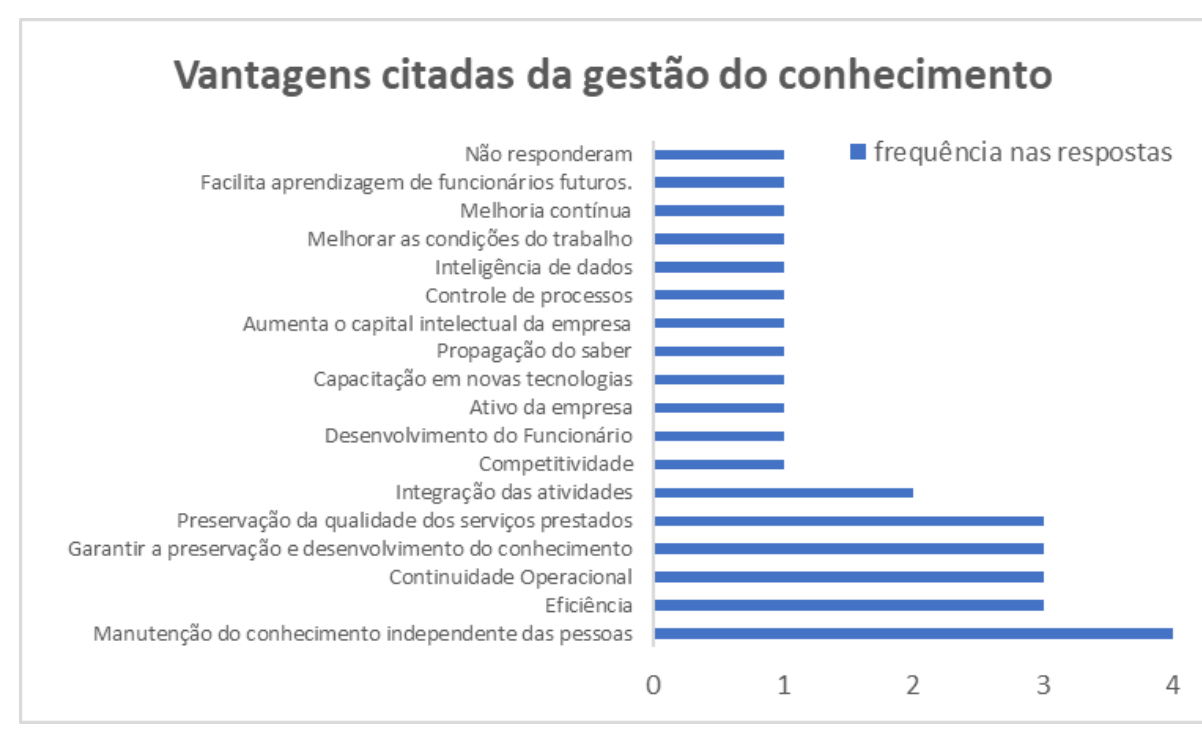

Fonte: Própria Autora (2019)

Foi solicitado que as empresas listassem vantagens enxergadas por ela na gestão do conhecimento, foram dadas diversas respostas diferentes, mas tiveram seis que foram citadas mais de uma vez. Dentre elas, manutenção do conhecimento independente das pessoas foi a que mais apareceu, sendo citada em quatro respostas. Seguida dela vieram a 
eficiência, a continuidade operacional, a preservação e desenvolvimento do conhecimento, e preservação da qualidade dos serviços prestados, que cada uma delas foram citadas três vezes, e a última que foi citada apenas duas vezes foi a integração das atividades. Embora a maioria delas estejam interligadas, é válido tratar de cada uma separadamente.

Manutenção do conhecimento independente das pessoas: Essa vantagem está relacionada completamente com o desligamento de funcionários. O capital humano é intangível, e não pode ser gerenciado da mesma forma que empresas gerenciam produtos, tecnologias etc. Um dos motivos para tal é que são os funcionários que detêm o conhecimento não a empresa. Sendo assim, ao saírem da empresa, esses funcionários levam consigo o seu capital humano, e qualquer investimento que a empresa tenha feito em seu treinamento e desenvolvimento fica perdido (BOHLANDER, 2005, p.09).

$E$ é aqui que entra uma das vantagens da gestão do conhecimento, uma vez que por sua definição, é o processo de obter, gerenciar e compartilhar o conhecimento dentro de uma organização (OLIVEIRA, 2006). As empresas fazem o processo de gerenciar e compartilhar o conhecimento, através de ferramentas de gestão, onde é possível arquivar o conhecimento em alguma plataforma, passando assim a ficar preso à empresa e não apenas a um funcionário em específico, e estando disponível para que outros funcionários tenham acesso à ele.

Eficiência: também está relacionada a definição da gestão do conhecimento, pois ao ficar armazenado em um lugar para que possam acessá-lo, independentemente de uma pessoa apenas, faz com que o trabalho possa ser feito de forma muito mais rápida, simples e com menos chances de gargalos, perdas de tempo e ruídos na comunicação. Por exemplo, permite que a consulta a uma determinada informação seja muito mais simples e rápida, digamos que um funcionário precise de uma determinada informação de outra área para poder desempenhar uma atividade, então com a gestão do conhecimento, bastaria o mesmo entrar na plataforma onde determinado conhecimento está armazenado e o consultar diretamente, sem precisar perder tempo de trabalho correndo atrás da pessoa que é "responsável" por aquelas informações.

Continuidade Operacional: O conhecimento estando armazenado, e podendo ser acessado através de algum canal, ou plataforma para tal, permite que a operação de alguma atividade da empresa não seja pausada mesmo que, o funcionário responsável por ela deixe a função, e isso é possível pois, os conhecimentos que são necessários para realização dessa atividade estão descritos e armazenados na plataforma da empresa, permitindo que a pessoa que for escolhida para desempenhar essa mesma função, não parta do zero, já vai poder dar continuidade no trabalho, uma vez que a forma como se deve desempenhar a função, ou informações que são necessárias para tal desempenho, estarão armazenados na empresa, seja em plataformas, sistemas exclusivos para isso, onde for. 
Preservação e desenvolvimento do conhecimento: Esta primeira está associada ao fato do conhecimento se manter na organização, e não restrito ao funcionário como já dito anteriormente. Porém essa segunda está relacionada, uma vez que pode ser criada uma base da dados, onde os funcionários alimentem essa base com os seus conhecimentos, e sendo assim, o conhecimento de um funcionário complementa o do outro, o que faz com que o conhecimento da organização como um todo esteja sempre em desenvolvimento. Por exemplo, supondo que um funcionário descreveu como uma determinada atividade deveria ser executada, supondo a montagem de um produto, porém já se passaram alguns anos, e surgiram então novas tecnologias e formas que facilitam esse processo de montagem, fazendo com que aquele que esteja descrito esteja obsoleto, sendo assim, um outro funcionário pode entrar nessa base e fazer alterações, desenvolvendo o conhecimento da organização.

Preservação da qualidade dos serviços prestados: Uma vez que a gestão do conhecimento, permite que o conhecimento seja, documentalizado, podendo estar descrito o passo a passo para de desempenhar uma determinada atividade, como por exemplo confecção de um certo produto. Ao estar documentado, há um padrão para o funcionário seguir, e diminuindo o risco de diferenciação entre o mesmo produto feito por pessoas diferentes. Sendo assim, com essa padronização, caso um funcionário seja demitido, e seja necessário colocar outro em seu lugar, este conhecerá o que deve ser feito e a forma como deve ser feito, o que faz com que o produto se mantenha igual, não variando de acordo com quem o produz.

Integração das atividades: Numa organização para que uma determinada área possa desempenhar sua função, e até mesmo para que certas atividades sejam executadas são necessárias informações de diferentes áreas, projetos, departamentos das empresas, e não apenas daquela área em si ou da área que está realizando a atividade. Sendo assim, havendo uma base de informações, onde são arquivados conhecimentos de todas as áreas, e partes da empresa, a troca de informações entre as áreas/pessoas se dá de forma mais simples, fácil e rápida, sem precisar parar o trabalho de ninguém para pedir determinada informação, por exemplo. Sendo assim, a gestão do conhecimento integra diferentes áreas e atividades, através do compartilhamento de suas informações através de um único canal.

\subsubsection{Como o conhecimento é gerado e codificado na organização?}


Gráfico 5 - Formas de geração e codificação nas empresas

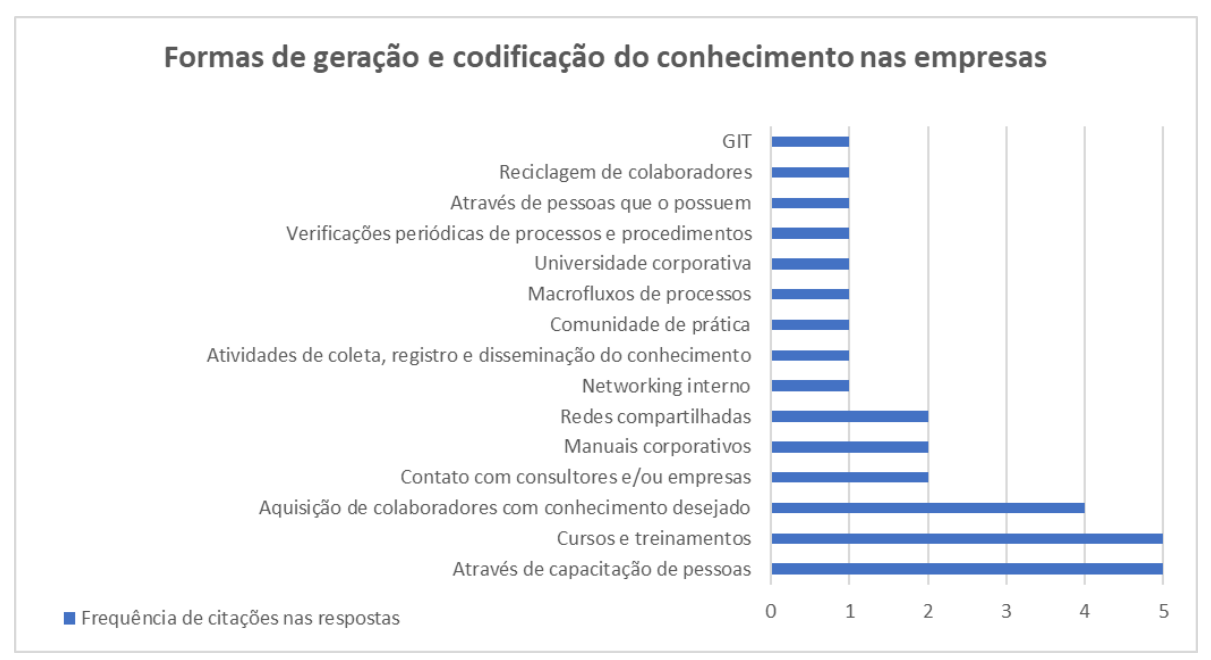

Fonte: Própria Autora (2019)

Segundo Oliveira (2006), a gestão do conhecimento é basicamente a realização de três processos, sendo o primeiro deles o processo de obtenção do conhecimento, seguido pelo processo de gerenciá-lo e por fim, de compartilhá-lo.

Sendo assim, quando foi perguntando sobre as formas de geração e codificação do conhecimento que as empresas adotam, a pergunta se relacionava com os dois primeiros processos de gestão do conhecimento, a obtenção e o gerenciamento.

A retenção do conhecimento, faz parte do processo de gerenciamento do mesmo, visto que apenas obter o conhecimento por um determinado tempo, e depois perdê-lo não faz sentido algum. Sendo assim, visando essa retenção as empresas necessitam criar medidas para estimular e desenvolver o potencial de seus funcionários.

Como formas de geração do conhecimento e codificação do conhecimento, pode-se destacar três atividades que foram as que mais foram citadas. Segundo essa pesquisa, a capacitação de pessoas é a principal fonte de geração e codificação do conhecimento, tendo sido citada cinco vezes. Essa forma de geração do conhecimento pode estar relacionada com o que Davenport e Prusak (2003) chamam de adaptação, quando eles citam quais as formas de se gerar conhecimento. Adaptação, pois, ao fazer a capacitação de funcionários, a empresa está buscando manter-se adaptada às mudanças que ocorrem externamente e internamente também, uma vez que se a empresa não se adaptar e estiver preparada para as mudanças a chances de fracassar o negócio são grandes.

Em seguida tendo aparecido a mesma quantidade de vezes aparece cursos e treinamentos, que estão diretamente relacionados ao primeiro item, capacitação de pessoas. Uma vez que, cursos e treinamentos são uma das ferramentas de capacitar os funcionários.

Sabendo-se as características da nova era em que todos nós vivemos, em que a globalização, competição e o aparecimento de novas tecnologias e mudanças repentinas 
são desafios que empresas enfrentam diariamente, o conhecimento se torna uma vantagem competitiva. Partindo desse ponto, o conhecimento também está a todo momento sofrendo mudanças, sendo necessária uma atualização constante. A aprendizagem se encaixa nesse contexto por ser fundamental para a sobrevivência dessas organizações, uma vez que ela aumenta o conhecimento e o atualiza, desenvolve novas habilidades, melhora o desempenho e permite que os funcionários assumam novas responsabilidades. Ulrich (1998) menciona que as pessoas são que compõem as riquezas e o poder das organizações, visto que o conhecimento é o recurso organizacional mais importante das organizações.

E tanto a capacitação de pessoas e realização de cursos e treinamentos são formas de se obter aprendizagem.

A capacitação é basicamente a atualização, complementação e/ou ampliação das competências necessárias para realização de atividade que a pessoa exerce. Ou seja, fazer com que as pessoas se tornem habilitadas e qualificadas para exercerem determinada função.

Já o treinamento segundo Marras (2001) é um processo de assimilação cultural de curto prazo, que tem como finalidade fazer o repasse ou a reciclagem do conhecimento, habilidades ou atitudes relacionadas à execução de tarefas ou à otimização no trabalho.

A terceira forma de gerar o conhecimento que foi citada quatro vezes ao longo da pesquisa foi a aquisição de colaboradores com o conhecimento desejado. E essa é a primeira forma de se gerar conhecimento, segundo Davenport e Prusak (2003), uma vez que para eles a forma mais eficaz de gerar conhecimento é comprando-o. Visto que a capacitação e a realização de cursos e treinamentos são formas de se obter no final o conhecimento desejado para determinada função, a escolha de se contratar uma pessoa de fora que já possua este conhecimento também é uma saída para que ao final a empresa detenha o conhecimento desejado. Porém, ao fazer a aquisição desse funcionário, a empresa poupa recursos que teriam que ser gastos em treinamentos, capacitação, cursos com seus funcionários. Outro fator que pode influenciar nessa escolha também é o tempo, o prazo que a empresa tem de se realizar tal atividade, dependendo da situação, pode-se constatar que não haveria tempo suficiente para fazer a capacitação de seus funcionários, e então a melhor escolha seria contratar alguém que já o possuísse. Isso se aplica também a fazer contato com consultores e empresas, que também foram formas citadas nas pesquisas. Realizar o contato com consultores e empresas pode ser visto como uma forma de "alugar" o conhecimento dessa entidade durante um tempo determinado, que é a segunda forma de geração do conhecimento citada por Davenport e Prusak (2003).

A realização de manuais corporativos foi a forma de codificação do conhecimento que mais foi citada nas respostas. Visto que para Davenport e Prusak (2003) o grande 
objetivo da codificação é apresentar o conhecimento de uma forma mais acessível para as pessoas que dele precisam, essa realização de manuais se aplica diretamente nisso. Pois neles são colocadas informações que são úteis e necessária para realização de atividades da empresa em um só lugar permitindo que o conhecimento esteja muito mais acessível para as pessoas. Geralmente esses manuais possuem objetivo de fornecer regras, diretrizes e padrões que devem ser cumpridos para determinada atividade.

E a codificação desse conhecimento é o que permite que a empresa retenha o conhecimento nela, passando a não ser dependente de apenas uma pessoa que seria responsável por determinada informação, por exemplo. São as formas de codificação que permitem que as empresas possam ter mais "liberdade", diminuindo as chances de sofrer poder de barganha de determinado funcionário, se por ventura o mesmo tiver que se desligar da organização.

\subsubsection{Como o conhecimento é disseminado nas empresas?}

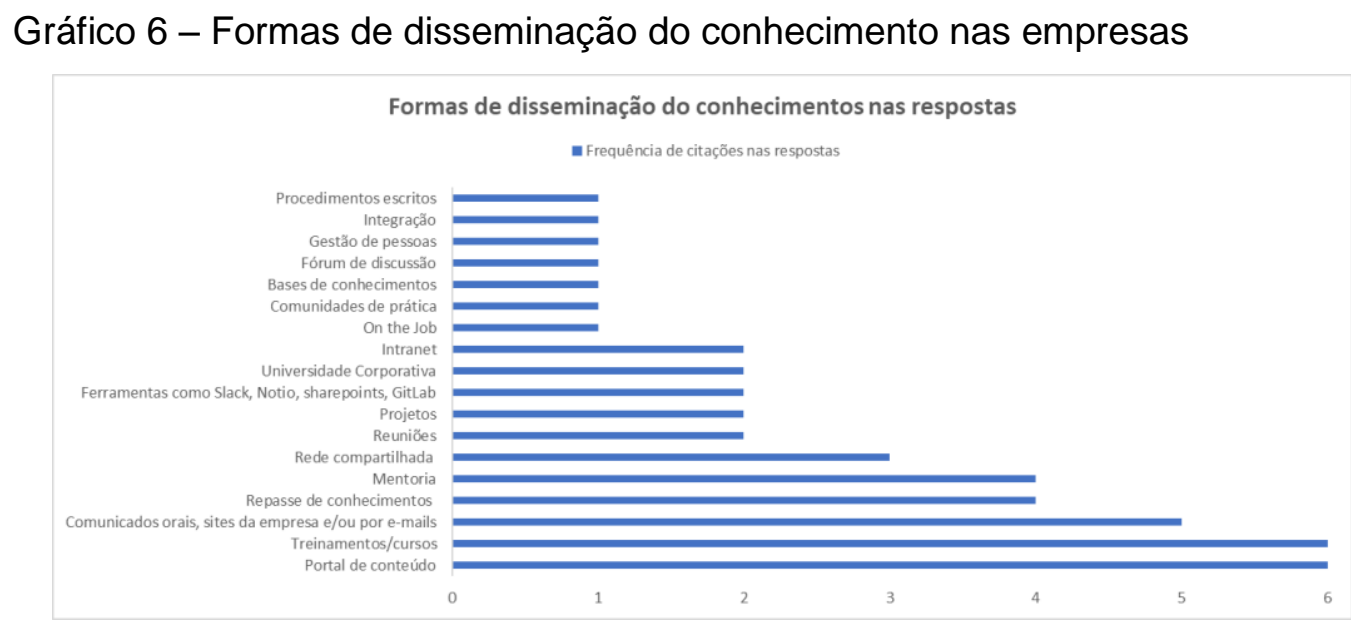

Fonte: Própria Autora (2019)

A disseminação do conhecimento, está dentro do terceiro processo compartilhamento de conhecimento-, que os três existindo juntos formam a definição de gestão do conhecimento na visão de Oliveira (2006).

Ao realizer a disseminação do conhecimento, a empresa está compartilhando-o. E este processo está atrelado a vantagens e benefícios que a gestão do conhecimento traz para as organizações. Podemos ver nessa pesquisa que uma das principais vantagnes e beneficios que a gestão do conheicmento gera é a diminuição da dependencia da empresa em um funcionário, isso por que atraves de ferramentas de obtebção e codificação do conhecimento, permitem que um funcionário transmita para a organização o seu conhecimento, fazendo com que este fique preso também a organização, diminuindo o risco da empresa de perdê-lo caso o funcionário seja desligado da empresa, por exemplo. 
Dito isso, é possivel observar o que foi respondido pelas empresas no questionário.

Ao ser questionado quais são as ferramentas que as empresas utilizam como forma de disseminar o conhecimento dentro dela, algumas dessas ferramentas tiveram um maior destaque. Sendo elas: portal de conteúdo e realização de treinamentos e cursos, ambas foram citadas seis vezes. Seguida delas veio a disseminação por meio comunicados orais, sites da empresa e por e-mails, com cinco citações, e por fim, repasse de conhecimento e mentoria ambas sendo citadas quatro vezes. Essas ações adotadas de disseminação do conhecimento, confirma o que foi dito por Davenport e Prusak (2003), que a transferência do conhecimento vai desde de ações mais simples - como nesses casos, por comunicados orais, site, e-mails até ações mais estruturadas como reuniões específica para discutir determinado assunto.

Esses portais de conteúdo nada mais são do que um local central feito para disponibilizar diversas informações a um público-alvo, que nesse caso são os próprios funcionários das empresas. Os portais de conteúdo possuem o objetivo de facilitar o acesso e compartilhamento de informações. Onde nele as informações podem ser colocadas pelos próprios funcionários que as detenham, permitindo que outros funcionários possam ter acesso a essa informação de maneira mais rápida e eficiente, sem precisar dispender tempo indo atras do proprio funcionário "dono" daquela informação.

Como já discutido anteriormente, a realização de cursos e treinamentos é uma forma de aprendizagem, de se obter conhecimento, ao mesmo tempo que é uma forma também de compartilha-lo. Uma vez que a pessoa que esta "dando" este treinamento, está compartilhando-os com os "alunos". Além disso, nessas empresas é muito comum que os próprios funcionparios que já possuem o know-how de determinada função deem treinamentos e cursos para outros funcionários que precisam ou desejam desempenhar ou entender sobre esta atividade. Ou seja, o conhecimento está deixando de pertencer a apenas uma pessoa, passando a conter em várias outras, tendo sido assim disseminado.

Toda a comunicação, seja oral, escrita, é uma forma de realizer a disseminação de informações, de conhecimentos. Para que todos os outros tipos de ferramentas de disseminação do conhecimento possam ser realizadas, é necessário a existencia desta. $A$ disseminação por meio de portal, por exemplo, é uma forma de comunicação escrita. Já a disseminação por meio de cursos e treinamentos é em sua maioria das vezes oral e escrita. Porém, as empresas que citaram essa forma como forma de disseminar o conhecimento, podem ser consideradas que o fazem de uma forma não tão eficiente. Foi dito que eles disseminam o conhecimento através da comunicação oral, onde uma pessoa compartilha com outra o conhecimento, porém essa forma de compartilhamento não é muito efetiva quando se trata de uma gestão do conhecimento, pois o acesso a esse conhecimento, informação ainda fica difícil, uma vez que passa de uma pessoa para outra pessoa, não 
sendo documentado em nenhum lugar para que outra pessoa possa accessá-lo sem precisar ir atrás das pessoas dominates dele.

O repasse de conhecimento citado como uma das formas de disseminação do conhecimento, pode se aplicar em todas as outras formas de disseminação também abordadas nesta pesquisa. Uma vez que por sua definição, a disseminação do conhecimento nada mais é que o repasse do conhecimento, podendo ele ser através de portais, cursos e treinamentos, comunicados orais, escritos, etc.

Já a mentoria ou mentoring, em inglês, segundo Batista (2006,p.15) é uma forma do desempenho na qual um mentor (participante expert) modela as competências de um indivíduo ou grupo, observa e analisa o desempenho deles e retroalimenta a execução das atividades do indivíduo ou grupo.

Ou seja, nada mais é do que um acompanhamento de forma técnica, emocional e estratégica, feito por uma pessoa mais experiente naquela atividade, que visa ajudar a pessoa que está sendo orientada a alcançar os resultados da melhor forma possível, fazendo assim um compartilhamento de experiencias e de geração do conhecimento.

\subsubsection{Como o conhecimento tático é transformado em explícito na empresa?}

Gráfico 7 - Formas de transformação do conhecimento tático em explícito nas empresas

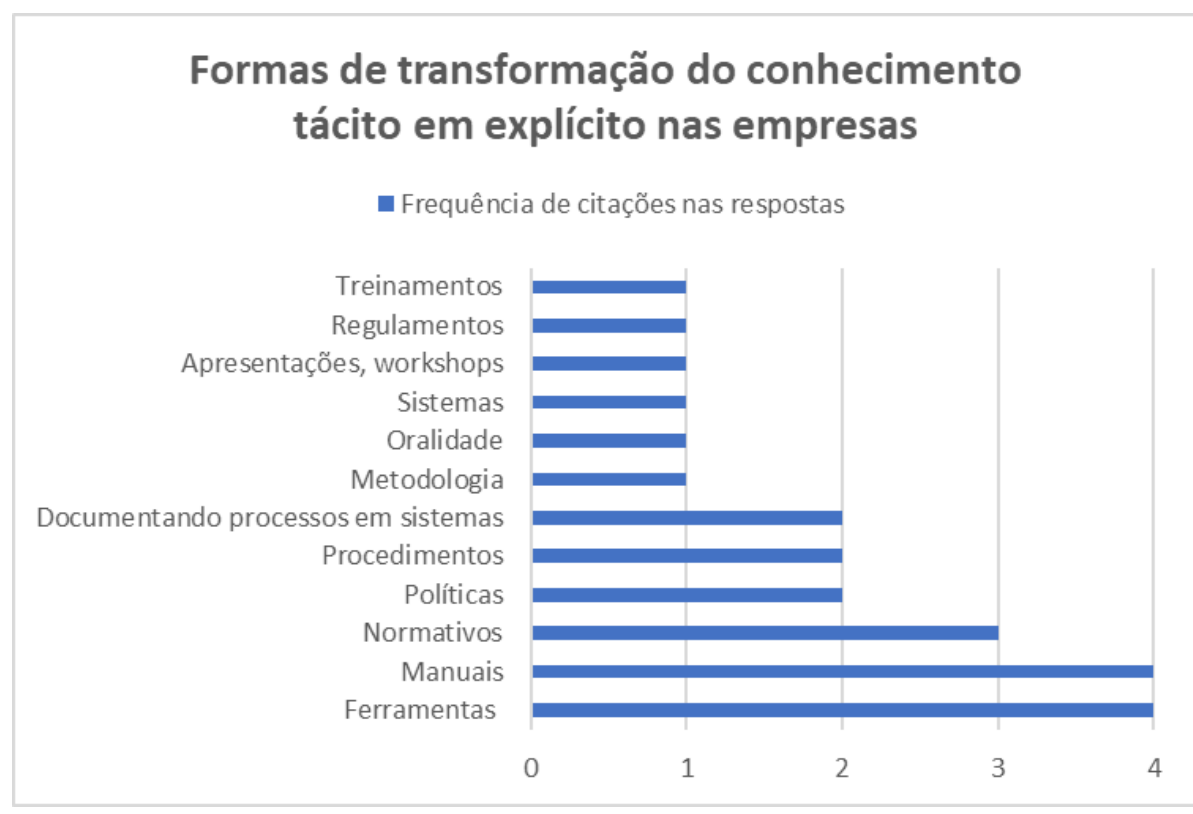

Fonte: Própria Autora (2019)

Podemos observar o que foi respondido pelas empresas quando foram questionadas que práticas elas realizavam visando transformar o conhecimento tácito em explícito. 
As práticas que mais foram citadas e por isso terão um destaque foram: através de ferramentas, manuais (ambas citadas quatro vezes) e através de normativos (citadas três vezes).

Ferramentas foram citadas, visto que as empresas passam o conhecimento que estão "na cabeça das pessoas" - os chamados "conhecimentos tácitos", definido por Nonaka e Takeushi (1997) como sendo o conhecimento presente na mente humana, como sua expressão em forma tangível, física é difícil, podendo ser avaliado por meio da ação, para um sistema onde esse conhecimento possa ter fácil consulta, conhecimento explícito, definido por Nonaka e Takeushi (1997) como sendo conhecimento que pode ser expressado em linguagem formal, transmitido com facilidade, podendo ser sistematizado e comunicado. Não foram citadas quais ferramentas as empresas adotavam exatamente para realizarem essa conversão. O que foi dito por elas é que há um processo onde as pessoas que detêm o conhecimento, conseguem através dessas práticas alimentar um Sistema de compartilhamento de informações.

E sendo assim, isso se aplica tanto a manuais quanto a normativos. Onde a pessoa transfere o conhecimento em sua mente, para um "papel", fazendo sua documentação, compartilhando suas experiências, e de que forma ela pratica aquela função ou de que forma ela adquiriu esse conhecimento, podendo fazer comparações e usos de analogias para tentar facilitar essa documentação, expressão numa forma física.

\subsubsection{Ferramentas tecnológicas que facilitam a utilização do conhecimento}

Gráfico 8 - Ferramentas utilizadas para facilitar a utilização do conhecimento

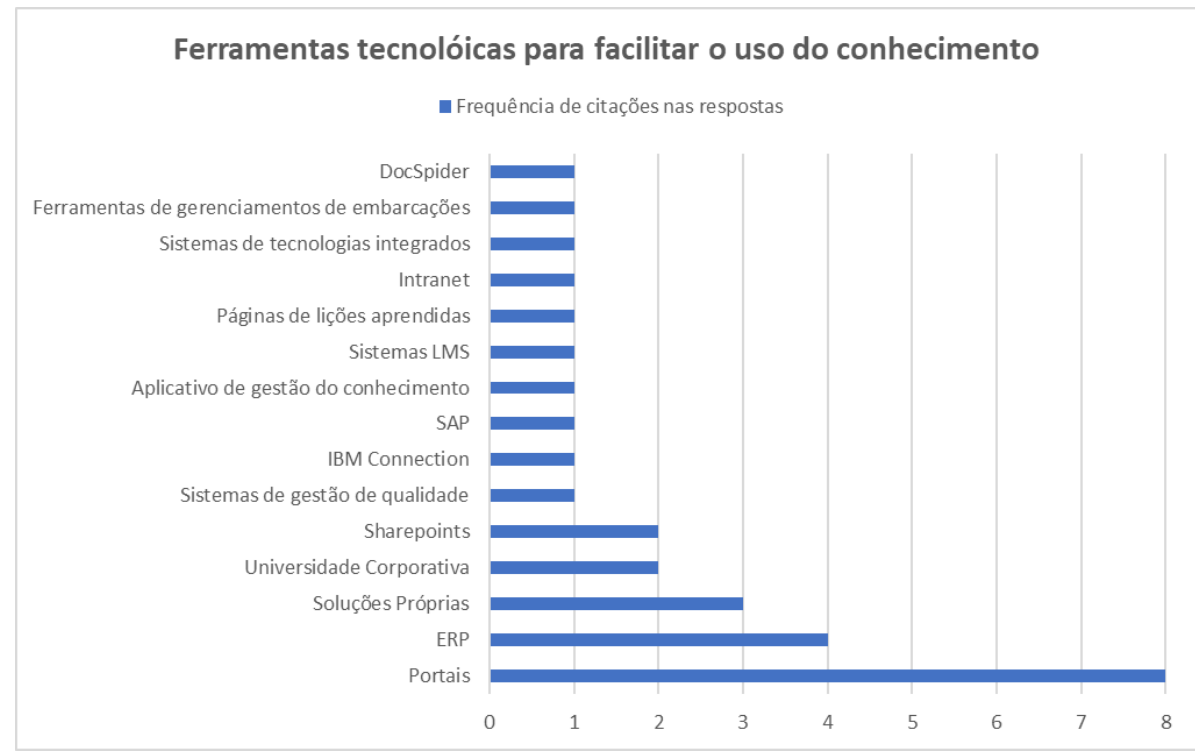

Fonte: Própria Autora (2019) 
Como é possível observar no referencial teórico desta pesquisa, na parte de "origem da gestão do conhecimento", há diversos fatores que podem justificar o surgimento da gestão do conhecimento. Mas o fator principal que desencadeou tal surgimento foi o início da globalização, com o surgimento da internet, que é um dos principais facilitadores para divulgação, transformação e criação do conhecimento.

Sendo assim, pode-se observar no gráfico 8 , que ao serem perguntados quais ferramentas tecnológicas mais facilitam o conhecimento nas empresas, o portal foi a ferramenta que mais foi citada, num total de oito vezes, em seguida vem o Sistema de Integração de Informações ERP, sendo citado quatro vezes, seguido por soluções próprias das empresas que foram citadas três vezes.

Assim como em "formas de disseminação do conhecimento" o portal foi o que mais foi citado. Isso se deve ao fato de que o portal é uma ferramenta tecnológica, pois é uma plataforma online, que permite que um número grande de usuários tenha acesso à ele, e possam alimentá-lo com informações. E assim, fazendo com que diversas pessoas, de diversas áreas diferentes tenham acesso às informações necessárias para desenvolverem suas atividades em um só lugar, otimizando assim o seu tempo, diminuindo chances de ruídos de comunicação etc.

O Sistema é ERP, sigla que vem do inglês (Enterprise Resource Planning), é um sistema de gestão empresarial, onde há uma series de atividades gerenciados por software ou por pessoas que ajudam a gestão dos processos da empresa. Sendo sua finalidade facilitar o fluxo de informações de uma organização visando otimizar tomadas de decisões, pode-se entender o por que de ser a segunda ferramenta mais citada. É uma ferramenta que faz uma integração entre diversas áreas, através da retenção de informações dessas áreas, que permite a troca de informações entre elas. Assim como outras ferramentas tecnologias, o ERP facilitando o acesso e por consequência o uso dessas informações e dos conhecimentos dos funcionários que o utilizam.

Não foram citadas quais são as soluções próprias que as empresas desenvolveram para tal, e muito menos foram explicadas como elas funcionam. Partindo do pressuposto de que são ferramentas tecnológicas, pode-se acreditar, então, que são softwares desenvolvidos para a própria empresa, que possuem uma finalidade de integrar informações entre as áreas, que permitem o armazenamento de informações e o seu compartilhamento, pois senão não teria como facilitar o uso do conhecimento se as soluções próprias não estiverem relacionadas com a geração, armazenamento, gerenciamento e disseminação do conhecimento. 


\subsubsection{A empresa realizou corte de funcionários recentemente?}

Gráfico 9 - Corte de funcionários

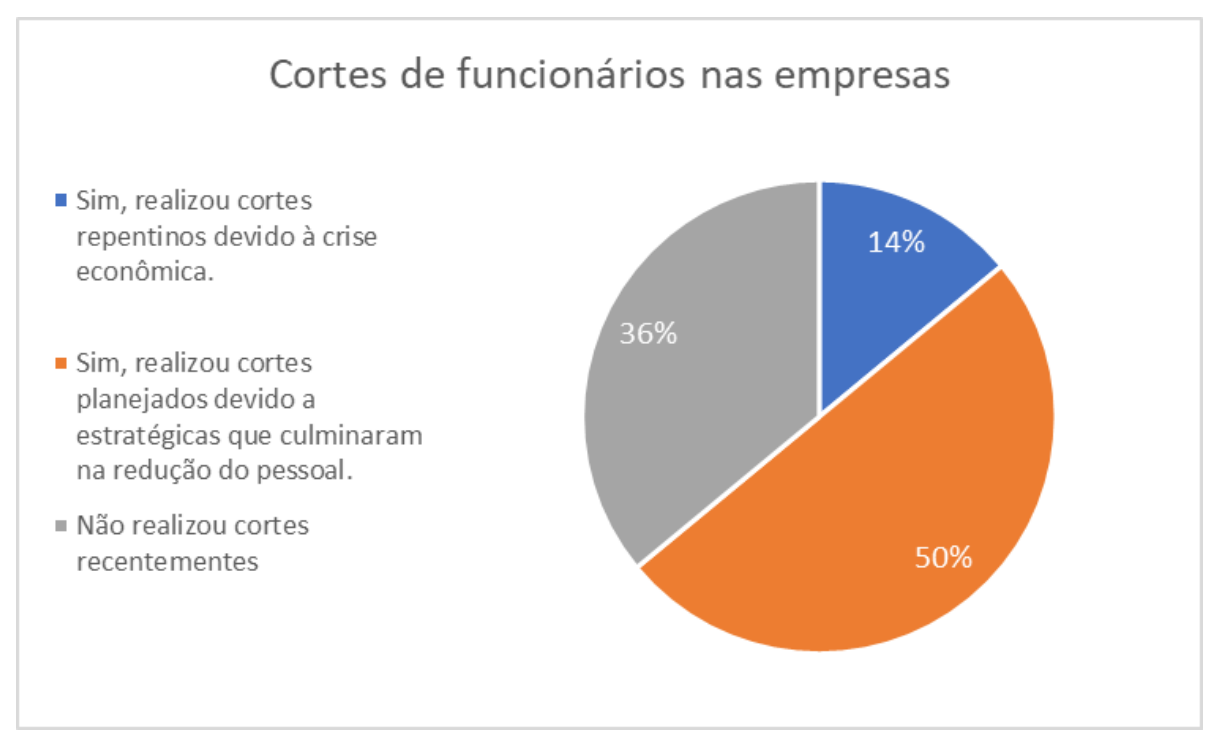

Fonte: Própria Autora (2019)

Visto que a gestão do conhecimento está muito atrelada a retenção do conhecimento para a empresa, visando não perder o conhecimento caso um funcionário que o detenha deixe a organização, foi perguntado as empresas se as mesmas tinham realizados cortes de funcionários, para que assim pudesse, depois, observar se as empresas que possuem a gestão do conhecimento, e que tiveram cortes de funcionários, se a adoção dessa gestão ajudou na retenção do conhecimento do funcionário que a deixou.

Sabendo-se que o país a partir de 2014, passou a enfrentar uma séria crise econômica e financeira, que fez com que muitas empresas demitissem seus funcionários, buscou-se saber se isto tinha influenciado o corte de funcionários das empresas participantes do questionário.

Sendo assim, constatou-se que 50\% das empresas responderam que sofreram sim desligamentos de funcionários, porém, que isto não estava relacionado a crise, mas sim a uma estratégia da empresa. $36 \%$ das empresas responderam que não realizaram corte de funcionários, e 14\% admitiram que fizeram o corte e que ele foi acarretado pela crise brasileira de 2014.

Podemos deduzir que mesmo metade das empresas afirmando que sofreram desligamentos por causa da estratégia da empresa, que essas demissões sofreram influências da crise econômica do país. Sabendo-se que para conseguir sobreviver a esses períodos críticos é necessário realizar corte de despesas, que inclui reduzir investimento e também enxugar o número de funcionários. Com isso, podemos deduzir que tenha sido feito uma análise de custo e benefício, sabendo-se que a estratégia da empresa estaria vinculada 
a sobreviver a este período de crise, ela teria que realizar redução de custos e despesas, e aproveitou isso para identificar quais funcionários teriam menos impacto na empresa caso fossem demitidos.

\subsubsection{Quais critérios nortearam os desligamentos?}

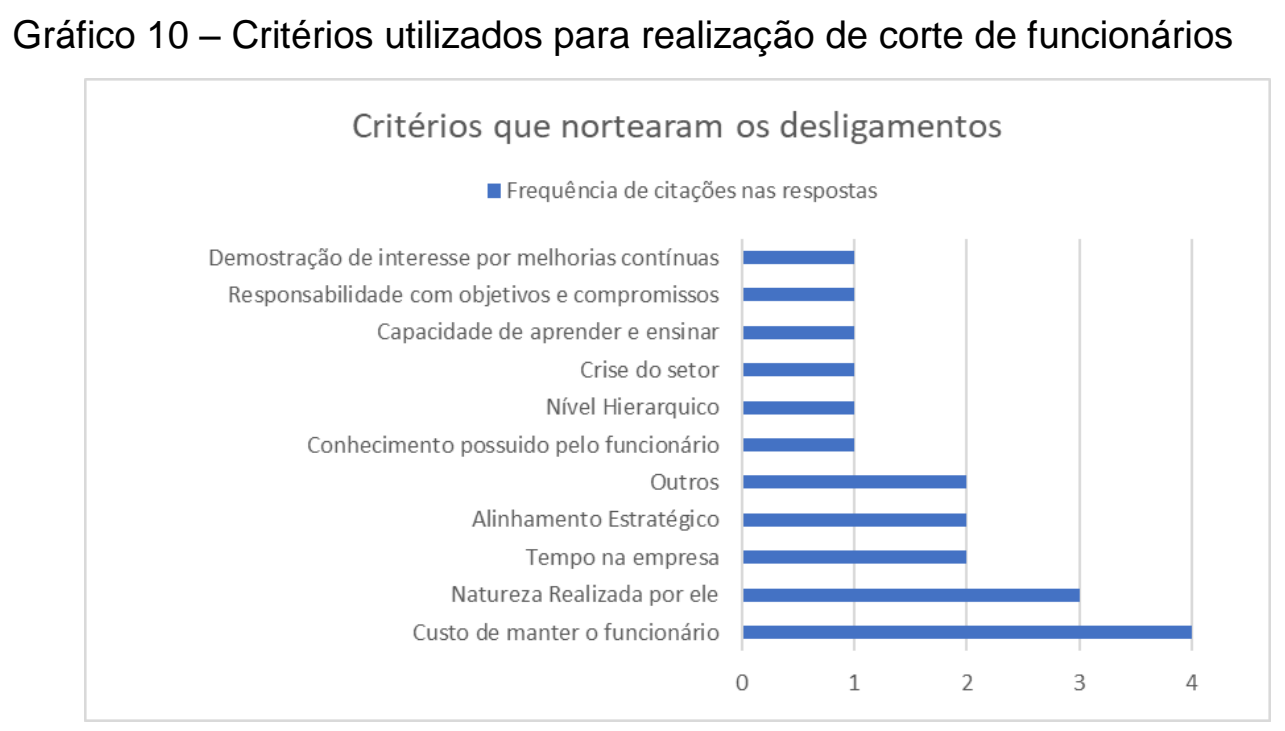

Fonte: Própria Autora (2019)

Visto que algumas empresas responderam que realizaram corte de pessoal, foi questionado quais os fatores que nortearam essa decisão. Podemos observar no gráfico 10, que o critério que mais obteve voto, foi o custo de manter o funcionário. Esse critério está muito associado ao período de crise, como já foi citado anteriormente, a crise exige que empresas realizem alguns ajustastes para sobreviverem a queda de produção e do faturamento até que esse período se encerre. E essas medidas por muitas vezes vão desde reduzir os investimentos a cortar funcionários, e a razão para este último seria o alto custo com o Quadro Funcional.

O Segundo critério mais utilizado foi o de natureza realizada por ele, que este pode estar muito relacionado com a consciência da importância da gestão do conhecimento. Uma vez que foi levado em consideração a atividade realizada pelo mesmo, e provavelmente, para tomar a decisão de qual seria demitido, tiveram que analisar a área que tem menos impacto com a atividade da empresa como um todo, a área que tem menos necessidade de um conhecimento específico, que seja mais fácil de ao passar a crise substituir o funcionário que fora demitido, pois não possuía um nível elevado de know-how.

O terceiro critério que mais apareceu foi o de tempo na empresa, que pode-se entender como as pessoas mais velhas teoricamente são as pessoas que possuem mais experiência naquela atividade, possuem um know how maior, e portanto não podem ser 
desligadas facilmente, uma vez que entendem mais da atividade da empresa, e que iriam ter um impacto maior na mesma caso fossem cortadas. Pode-se dizer também, sob um nova perspectiva, de que as empresas poderiam cortar as pessoas mais velhas, uma vez que elas tendem a ser mais resistentes às mudanças, às tecnologias, e mais fechadas a aprender e se manter atualizadas, se em comparação com uma pessoa que acabara de entrar na empresa, que tem anseios de crescer e construir uma carreira nela.

\subsubsection{A empresa considera que ao demitir um funcionário conseguiu manter o conhecimento dele dentro da empresa?}

Gráfico 11 - Consideração de empresas que conseguiram manter o conhecimento do funcionário demitido.

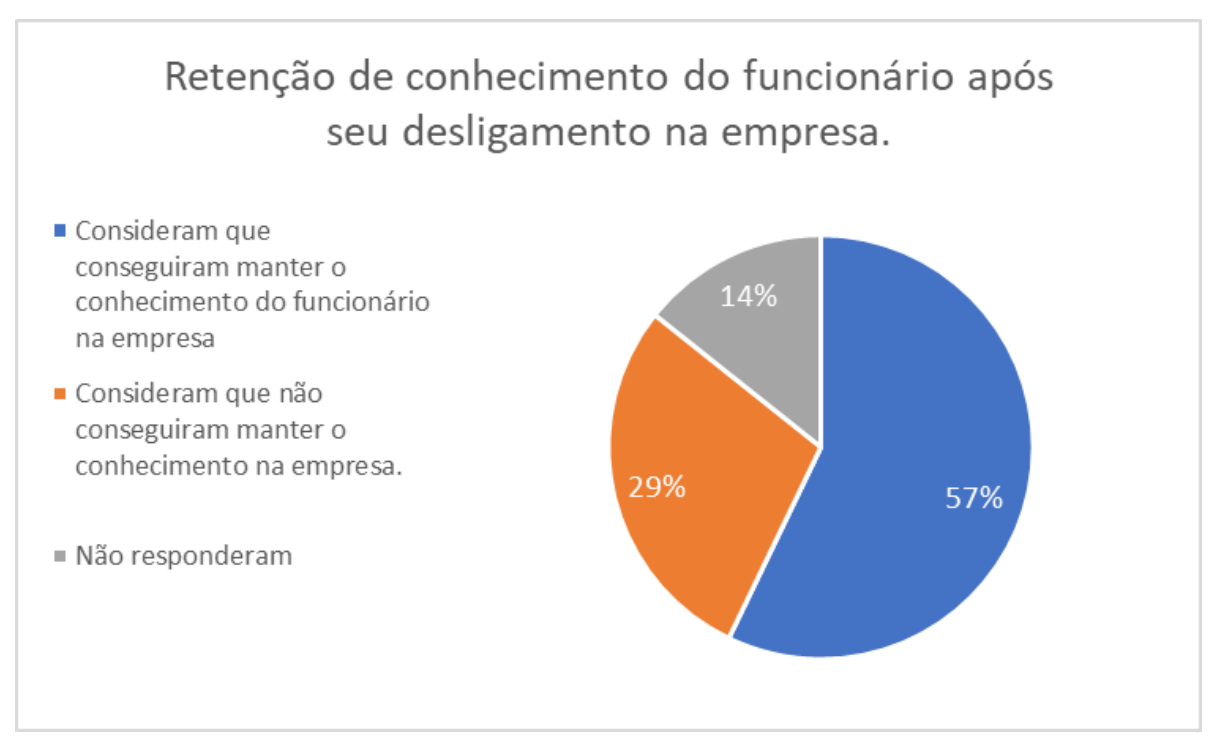

Fonte: Própria Autora (2019)

Visando entender se a aplicação da gestão do conhecimento, estava dando resultados positivos, e por consequência sendo aplicada de maneira correta, foi perguntado para as empresas se na visão delas elas consideravam que conseguiram reter o conhecimento de um funcionário após ele deixar a organização.

Um pouco mais da metade das empresas responderam que consideram que conseguiram reter o conhecimento dentro delas (cerca de 57\%), 29\% das empresas responderam que consideram que não conseguiram reter o conhecimento dentro dela, e 14\% não souberam opinar, e preferiram não responder a pergunta.

Para as empresas que responderam que conseguiram manter o conhecimento, foi perguntado como os processos e ferramentas colaboraram para que acontecesse a manutenção desse conhecimento. As respostas obtidas podem ser observadas no gráfico 12. 
Gráfico 12 - Processos e ferramentas que colaboraram para manter o conhecimento.

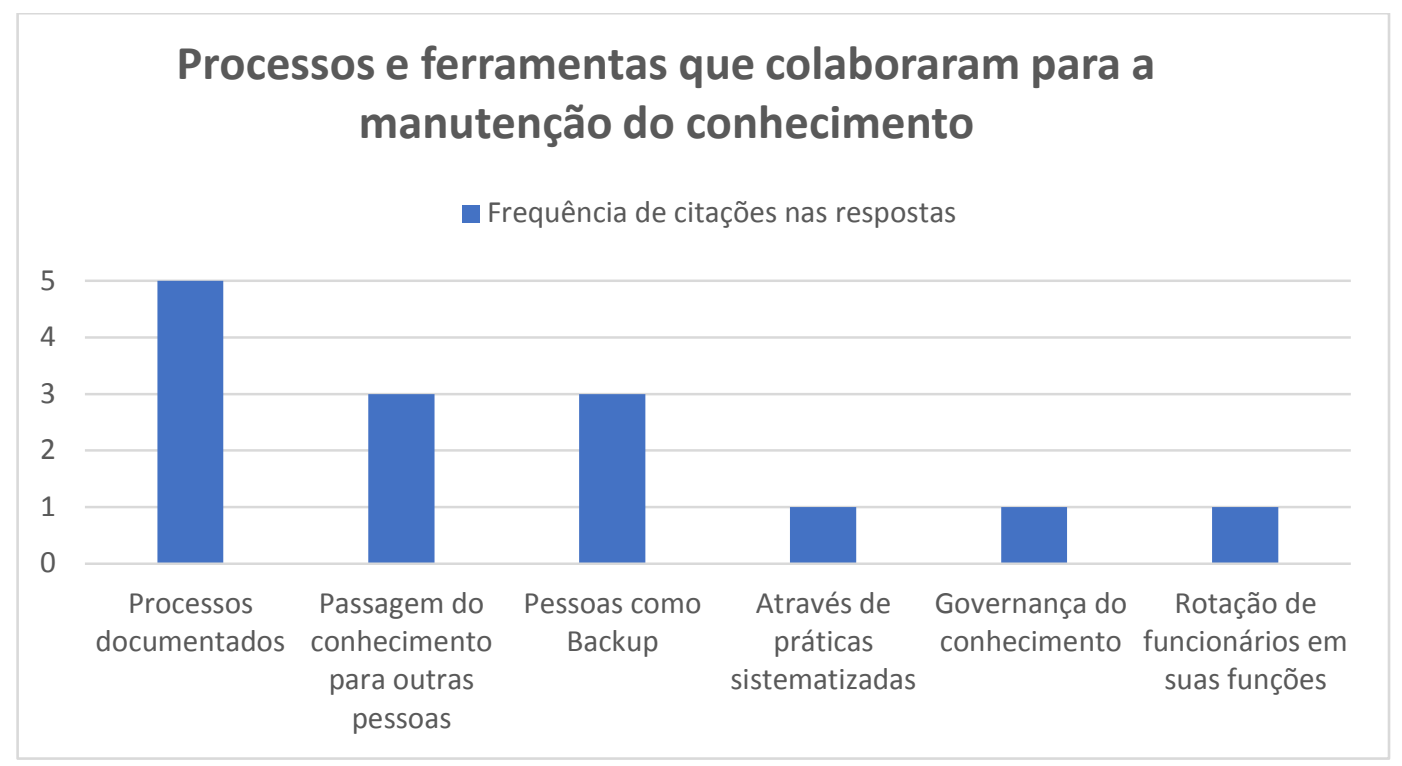

Fonte: Própria Autora (2019).

Pode-se identificar então que a melhor forma para se reter o conhecimento dentro das empresas foi atarvés da documentalização dos processos. Onde a pessoa que retem alguma informação, conhecimento, passa o conhecimento tácito para algum documento, plataforma, ou o que seja, que permita que ele deixe de ser possuido por apenas uma pessoa e passe a ser possuído pela organização como um todo, passando a ser um conhecimento explícito.

A segunda forma que as empresas acreditam que ajudaram elas a reterem o conhecimento, foi justamente a troca de informações entre as pessoas, onde a pessoa que detinha determinado conhecimento, passava-o para outra pessoa. Vale destacar, que geralmente essa forma de disseminação do conhecimento, tem um impacto pequeno na organização, uma vez o que conhecimento passa ser intrinsico a uma pessoa, e passa a ser intrisico a outra pessoa, e não à organização como um todo, mas de qualquer maneira é melhor do que apenas uma pessoa ser possuidora do mesmo. Aqui o conhecimento passa de uma mente para outra mente, não sendo codificado, nem documentalizado, nem inserido em nenhuma plataforma.

E pode-se observar também, que a terceira forma que teve mais de uma citação, foi obter pessoas como backup. Essa forma está um pouco relacionada com a forma acima retratada, porém nessa daqui podemos imaginar que além de possuir a troca de informações, esse conhecimento nunca pertence à apenas uma pessoa na organização, mas sim pelo menos outra, onde caso uma pessoa deixe a organização, o conhecimento vai estar com a outra, esta ultima funcionando como um backup. 
Como houveram empresas que responderam que não conseguiram reter o conhecimento, foi perguntado então, o que poderia ser, na opnião da respondente, aperfeiçoado na gestão do conhecimento a fim de impedir a perda do conhecimento. Podemos observar as respostas no gráfico 13.

Gráfico 13 - Soluções para o aperfeiçoamento na gestão do conhecimento para impedir a perda.

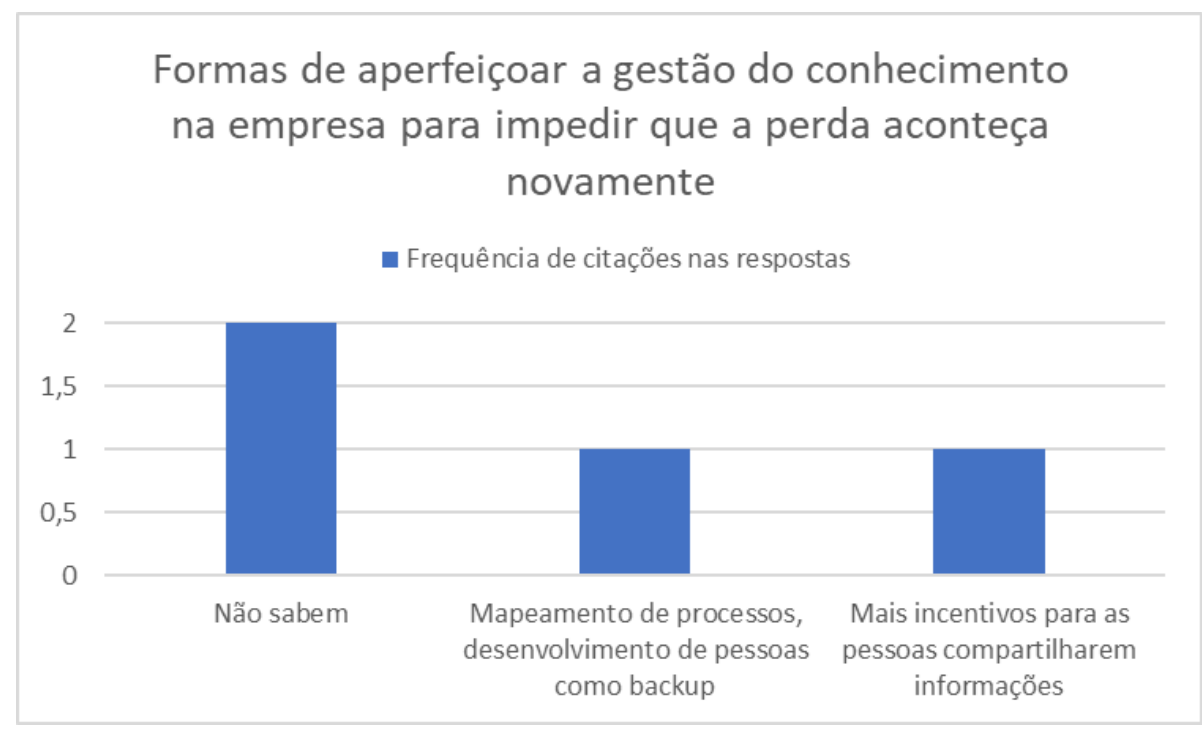

Fonte: Própria Autora (2019)

Das empresas que não conseguiram reter o conhecimento, apenas duas responderam de que forma eles acreditam que a empresa poderia aperfeiçoar a gestão do conhecimento delas a fim de impedir perdas de conhecimento futuros. As outras responderam que não sabiam o que poderia ser aperfeiçoado.

Uma empresa respondeu que poderia ser feito um mapeamento de processos, e adoção de uma política de pessoas como backup. Que conforme suas definições e benefícios já foram citados neste trabalho.

E a segunda respondeu que as pessoas dentro dessa organização possuem uma resistencia em compartilhar informação, ainda há um pensamento de que a informação é de uma pessoa, e que ao passar essa informação a outra pessoa de outra área, ele poderia estar "perdendo" alguma vantage de se destacar, de fazer sua área ter mais destaque do que a outra. Sendo assim, respondeu que é necessário um maior incentivo para que os funcionários compartilhem informação, que eles enxerguem que compartilhar informações entre pessoas, e entre áreas é uma forma da empresa conseguir se aperfeiçoar, ser mais eficiente e eficaz, deixando de lado essa concorrência entre as diversas áreas das empresas. 


\subsubsection{De que forma a gestão do conhecimento minimiza a perda do conhecimento?}

Gráfico 14 - Formas que a Gestão do Conhecimento minimiza a perda do conhecimento

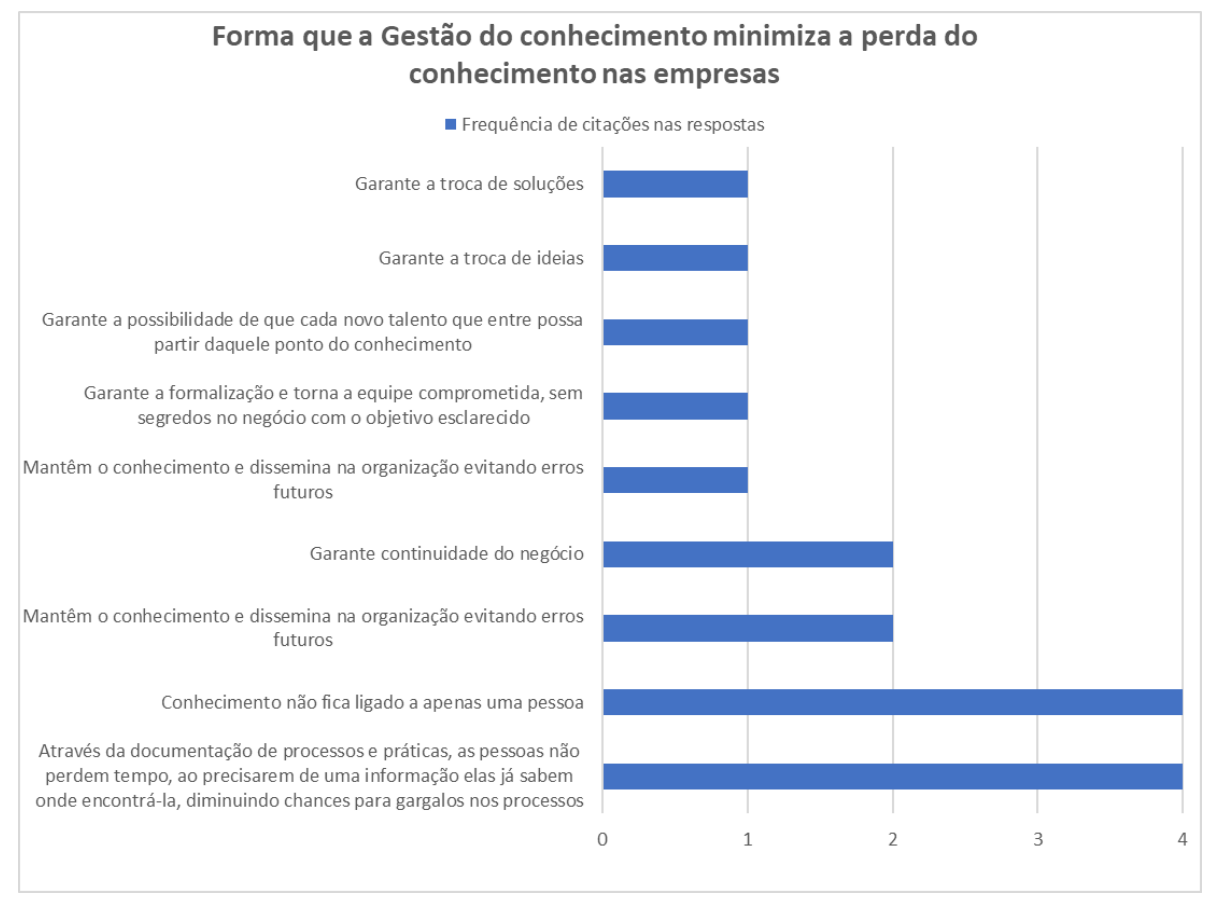

Fonte: Própria Autora (2019)

Sabendo-se que uma das grandes vantagens e finalidades da gestão do conhecimento é evitar a perda do conhecimento, já que este é o grande triunfo que uma organização obtém, devido à características dos ambientes em que estão inseridas. Foi perguntado as empresas, se elas acreditavam realmente que esta prática minimiza a perda de seu conhecimento. Todas responderam positivamente a esta pergunta, e então foram questionadas de que forma elas acreditavam que essa gestão minimizava que o conhecimento fosse perdido.

Serão analisadas apenas as quatro respostas que mais foram citadas, as duas primeiras tendo aparecido quatro vezes e as outras duas seguidas, tendo aparecido duas vezes.

A primeira delas foi que, através da documentação de processos e de práticas, as pessoas não perdem tempo ao precisarem de uma informação, uma vez que elas já sabem a onde podem encontrá-la, diminuindo chances para gargalos nos processos e otimizando suas operações. Essa documentação de processos e de práticas é uma forma de fazer uma gestão do conhecimento,que gere o conhecimento intrínsico de uma pessoa, para um documento onde o mesmo poderá ser acessado por diferentes pessoas. Caso a empresa não tenha essa gestão, isso pode levar a mesma a perder tempo (por exemplo, o tempo de 
ficar a procura de uma determinada informação, e consequentemente fazer uma tomada de decisão tardia), torna os procedimentos mais complexos e a organização acaba não otimizando as suas operações e processos.

Ou seja, a gestão do conhecimento, através de práticas de documentalização facilita as atividades do dia a dia da organização, pois permite que diversos funcionários insiram e tenham acesso ás informações que são necessárias para que eles realizem sua função, agilizando assim, processos da empresa que em sua maioria das vezes para serem executados precisam de informações de diferentes áreas. Por ser uma fonte onde a informação está a todo momento sendo atualizada, permite que os funcionários fiquem mais atualizados também, se não houvesse uma forma de agrupar essas informações em um só lugar, para uma pessoa que requer de informações de um outro setor para que ele possa cumprir com suas atividades, este funcionário provavelmente teria que ficar a procura da área responsável pela informação, perdendo tempo em que ele poderia estar adiantando suas funções, e também fazendo com que o outro necessite parar a atividade que está realizando para que possa concede a informação ao requerente.

E um problema que se desencadear é que, o tempo das pessoas são distindos, as vezes o funcionário necessita de uma informação para aquele momento, porém a pessoa que a possui não está disponível exatamente naquele momento, e isso gera um gargalo nas operações, já que o funcionário não poderia dar continuidade a sua função, pois depende de um terceiro para the conceder a informação. E isso é um problema que a gestão do conhecimento atraves da documentação de processos e práticas diminui, pois basta o funcionário ter acesso ao documento nos sistemas que possui determinada informação.

A segunda forma que auxilia a não perder o conhecimento e que foi citada também quatro vezes é "Conhecimento não fica ligado a apenas uma pessoa". E isso é possivel pois, uma vez que ele é documentalizado, digilitalizado, e disseminado para outras pessoas, o conhecimento passa a fazer parte da organizaçao, esta passa a ficar menos dependende do funcionário em si, uma vez que a informação passa a ser de todos e não somente de um.

A terceira forma que mais foi citada nas respostas foi "pois mantêm o conhecimento e o dissemina na organização evitando erros futuros" com duas citações. Isso está relacionado também ao arquivamento do conhecimento nas organizações. Essa resposta pode ser entendida, uma vez que fazendo a alimentação de informações, conhecimentos em uma plataforma onde eles fiquem arquivados, esse conhecimento passa a ficar aberto, acessível para todos da organização. Ficando acessível para todos, ele permite que pessoas troquem informações, troquem experiências, e soluções, fazendo com que um funcionário possa aprender com a experiencia do outro, evitando assim erros futuros e evitando que erros do passado sejam repetidos. 
Também tendo aparecido duas vezes como respostas, "garante a continuidade do negócio" é vista como um dos motivos da gestão do conhecimento minimizar a perda do conhecimento da organização. Uma vez que o conhecimento foi obtido, gerenciado através de práticas de documetalização e disseminado a outras pessoas por meio de portais online, por meio de comunicados, ou qualquer outra forma de disseminação, o conhecimento de uma determinada atividade passa para diversas pessoas, como já dito a cima, ele não fica preso a apenas uma pessoa, e assim a empresa não depende daquele funcionário portanto para que as operações tenham continuidade. Caso o funcionário tenha que ser desligado por qualquer motivo, o conhecimento daquela atividade que ele exercia fica na organização, permitindo que a nova pessoa que for exercer esta atividade, tenha um conhecimento prévio da mesma, conheça seu padrão e a forma como ela tem que ser desempenhada, permitindo que a operação da atividade não pare pois aquele funcionário deixou a empresa.

É possivel entender essa continuidade do negócio sob uma diferente perspectiva também. Sabendo-se que estamos na era da informação, onde a todo momento essa informação é transformada, atualizada, onde as mudanças no ambiente estão acontecendo a todo instante, onde o conhecimento se torna obsoleto também de forma muito mais rápida. A gestão do conhecimento, através das ferramentas de obtenção, de gerência, e disseminação do conhecimento, faz com que o conhecimento da organização seja a todo momento atualizado, e modificado, permitindo a todo momento a troca de informações entre os funcionários, a aprendizagem continua (através da capacitação, cursos, treinamentos, e até mesmo troca entre os funcionários), são fatores fundamentais para que a empresa possa continuar existindo, sem ser engolida por essa onda de mudanças continuas e por tamanha competitividade que se criou no ambiente moderno. Sabemos que nesse ambiente o diferencial competitivo é justamente o conhecimento, então, sendo assim, sem o conhecimento adequado as empresas não iriam conseguir sobreviver e nem dar continuidade as suas operações. Portanto, pode-se entender que a gestão do conhecimento evita a perda do conhecimento, permitindo a continuidade do negócio. 


\section{5.. Conclusão e Recomendações}

\subsection{Conclusão}

Um mundo com o avanço da globalização e com o avanço da internet, fez com que fosse possível uma maior aproximação entre nações e empresas, com um fluxo de troca de informações elevadíssimo, onde mudanças acontecem mais rápidas e constantemente. $\mathrm{E}$ por isso, em um mundo com essas características, onde o conhecimento se torna obsoleto muito mais rapidamente do que antes, a grande vantagem competitiva das organizações são os capitais humanos que a compõem, portanto, seus conhecimentos.

Porém, no contexto em que o Brasil está inserido, onde há uma recessão da economia, devido a crise política, as empresas se viram em um momento delicado. $E$ visando perdurar suas operações, e saírem com o menor prejuízo possível, as empresas buscaram formas de reduzir suas despesas, tomando medidas drásticas como o corte de funcionários.

É claro que esse corte de funcionário pode acontecer devido a diversos fatores, e não só por causa da crise. Como podemos observar no capítulo anterior, ele se dá muito ao fato de estar alinhado com as estratégias da empresa. Porém pode-se perceber, que muitas vezes a estratégia da empresa, uma vez que esta estava inserida em um ambiente de crise, sua estratégia poderia ser reduzir despesas, a fim de sobreviver a crise, e portanto, seria um corte relacionado a crise também.

Independentemente do fator que desencadeou o desligamento do funcionário, uma coisa é certa. Ao deixar a organização, esse funcionário pode acabar levando consigo todo o seu conhecimento, muitas vezes, até mesmo os investimentos em cursos e treinamentos que a empresa gastou com ele. Uma forma de prevenir que esse problema aconteça, é o objeto de estudo dessa pesquisa, a gestão do conhecimento.

Uma vez que a empresa possua e adote ferramentas de gestão do conhecimento, fazendo registro, divulgando, e gerando novos conhecimentos, o que antes era apenas o conhecimento individual de um funcionário, passa a ser parte da empresa e contribuir para o seu crescimento, criando vantagem competitiva para ela, preparando-a cada vez mais para enfrentar mudanças e incertezas.

Tendo em vista esse problema da perda do conhecimento através da demissão, objetivou-se realizar esse estudo, que tem como finalidade identificar de que forma a gestão do conhecimento minimiza essa perda, de fato, nas organizações. E esse objetivo do estudo 
foi cumprido, a partir da análise das informações obtidas pela aplicação do questionário aos respondentes.

Para que se fosse possível responder a pergunta "chave" do trabalho, foram realizadas pesquisas bibliográficas e de campo - por meio de um questionário com empresas que se encaixavam nas delimitações do estudo. O questionário foi feito através da ferramenta do Google, chamada "Formulários Google".

Para que se chegasse a resposta para a pergunta principal desta pesquisa, explicitada no tópico 4.2.12 "De que forma a gestão do conhecimento minimiza a perda do conhecimento", foi preciso antes, responder a algumas perguntas anteriores, que serviriam para que fosse possível atingir a principal. A primeira delas foi ver se a prática de gestão do conhecimento estava sendo praticada nas empresas, e em relação a esta, é possível concluir que sim, todas as empresas que responderam ao questionário possuem gestão do conhecimento, e a praticam, o que mostra que estas estão alinhadas a características da sociedade da informação. A segunda pergunta, era verificar se as empresas tinham realizado desligamentos de funcionários e quais os critérios que elas teriam utilizado para tal, esse questionamento foi feito uma vez que o objetivo do estudo era justamente a perda do conhecimento através de corte de pessoal. A terceira, foi levantar se as empresas ainda continuavam perdendo conhecimento, mesmo possuindo gestão do conhecimento, e foi concluído que sim, algumas empresas mesmo depois de adotarem ferramentas dessa gestão, não conseguiram reter o conhecimento do funcionário, o que demostra que a adoção possa não ter sido feita de forma adequada, ou até mesmo, que as ferramentas não estão sendo utilizadas de forma correta. E, por fim, a ultima pergunta a ser respondida pela pesquisa visando atingir ao objetivo do trabalho, era analisar as vantagens que a gestão do conhecimento estaria trazendo para as organizações que a adotassem, e pôde ser concluído, que as empresas enxergarem a gestão do conhecimento, como uma prática regada de vantagens para a organização, sendo algumas delas como "permite a manutenção do conhecimento independente das pessoas", "aumenta eficiência", "auxilia na continuidade operacional", "garante a preservação e desenvolvimento do conhecimento", dentre outras que podem ser vistas, juntamente com sua análise, no tópico 4.2 .4 do capítulo anterior e no gráfico 4 do mesmo.

Em suma, pode-se dizer que o objetivo deste trabalho foi alcançado, dado que foi estabelecido uma correlação entre as variáveis estudadas - as empresas e definir sua natureza, relacionando a gestão do conhecimento com a perda do mesmo, esclarecendo os fatores da gestão do conhecimento que contribuem para o fenômeno de minimização da perda deste. 


\subsection{Recomendações}

É possível considerar que uma vez que o estudo atingiu seu objetivo, ele contribui para um melhor entendimento sobre a importância da gestão do conhecimento para as organizações nos dias atuais. Porém, devido as grandes limitações do trabalho, como o tamanho da amostra, por exemplo, não pode ter sido suficiente para representar e responder sobre esse assunto de forma geral para todas as empresas. Esse estudo pode não ser uma verdade, que representa a maior parte das empresas, mostrando o movimento/respostas da organização perante ao ambiente de incertezas e de mudanças no qual estão inseridas.

Sendo assim, é aconselhável que seja feito um estudo, com uma maior profundidade, abrangendo empresas de uma região maior, ou até mesmo de todo o país, e com um tempo dispendido e trabalhado nele maior, e não apenas de seis meses como foi o caso da presente pesquisa, para que seja feita uma análise mais representativa das empresas como um todo.

O presente estudo, também pode ser utilizado como uma forma comparativa com o futuro estudo, confirmando suas conclusões ou invalidando-as. 


\section{6.. Referências Bibliográficas}

ALENCAR, Miriam. Gestão do conhecimento. Brasília, 2005. Disponível em: < http://repositorio.uniceub.br/bitstream/123456789/754/2/20100648.pdf> Acessado em 06 de Novembro de 2018.

ALVARENGA NETO, Rivadávia Correa Drummond de. Gestão do conhecimento em organizações: proposta de mapeamento conceitual integrativo. São Paulo: Saraiva, 2008

Ativos intangíveis. - Disponível em: <http://www.portaldecontabilidade.com.br/tematicas/ativosintangiveis.htm> Acessado em 06 de novembro de 2018.

BATISTA, F. F. (2006); "O desafio da gestão do conhecimento nas áreas de administração e planejamento das instituições federais de ensino superior (IFES)". Texto para Discussão, $\mathrm{n}^{\circ}$ 1181. IPEA, Brasília.

BENTO, Juliana; MASSUDA, Ely; URPIA, Arthur; BORTOLOZZI, Flávio. Práticas da gestão do conhecimento em recursos humanos em instituições de ensino superior a distância. Disponível em: <https://www.revistaespacios.com/a16v37n29/16372921.html>. Acessado em 27 de novembro de 2018.

BOHLANDER, George; SNELL Scott; SHERMAN Arthur. Administração de Recursos Humanos. São Paulo: Pioneira Thomson Learning, 2005.

Brasil entrou em recessão a partir do $2^{\circ}$ trimestre de 2014, diz FGV. (04 de Agosto de 2015). Fonte: G1. Disponível em: <http://g1.globo.com/economia/noticia/2015/08/brasilentrou-em-recessao-partir-do-2-trimestre-de-2014-diz-fgv.html>. Acessado em: 07 de novembro de 2018.

CAVALCANTI, Marcos; GOMES, Elisabeth; PEREIRA, André. Gestão de empresas na sociedade do conhecimento: um roteiro para a ação. Rio de Janeiro. Campus, 2001.

CHIAVENATO, Idalberto. Gestão de Pessoas: o novo papel dos recursos humanos nas organizações. Rio de Janeiro: Elsevier, 1999. 
Como a crise econômica afeta a vida da população brasileira. (09 de Maio de 2017). Contraponto Digital. Disponível em: <http://agemt.org/contraponto/2017/05/09/como-a-criseeconomica-afeta-a-vida-da-populacao-brasileira/>. Acessado em: 27 de novembro de 2018.

COUTINHO, L.D, DELFINO, L.M, \& COSTA, W.L. Pessoas: principal fonte de vantagem competitiva organizacional. Disponível em: $<$ https://www.aedb.br/seget/arquivos/artigos09/102_Pessoas_Principal_Fonte_de_vantagem _Competitiva.pdf>. Acessado em: 06 de Novembro de 2018.

DAVENPORT, H.D.; PRUSAK, L. Conhecimento Empresarial: como as organizações gerenciam seu Capital intelectual. Rio de Janeiro: Elsevier, 2003. 14를.

DESSLER, Gary. Administração de Recursos Humanos. 2. ed. São Paulo: Prentice Hall, 2003.

EBOLI, M.(s.d).: Gestão do Conhecimento como vantagem. Fonte: Associação Nacional dos Cursos de Graduação em Administração. Disponível em: <http://www.angrad.org.br/_resources/files/_modules/producao/producao_667_20121205183 4228e9c.pdf>. Acessado em: 07 de novembro de 2018.

FERREIRA, Aurélio Buarque de Holanda. Minidicionário Aurélio da Língua Portuguesa: Miniaurélio Eletrônico versão 5.12. 7. ed. rev. atual. 2004.

GERHARDT, Tatiana; SILVEIRA, Denise. Métodos de pesquisa. 1 ed. Universidade Federal do Rio Grande do Sul. Rio Grande do Sul: 2009. Disponível em: <http://www.ufrgs.br/cursopgdr/downloadsSerie/derad005.pdf>. Acessado em 27 de novembro de 2018.

HSM - Management. São Paulo. HSM do Brasil, n. 42, janeiro e fevereiro, 2004 - Bimestral. ISSN 1415-8868

MARQUES, Rosa Maria; N AKATANI, Paulo. O Brasil e a crise econômica: apenas uma marolinha? Disponível em: <http://www.pucsp.br/downloads/5_5_artigo.pdf>.Acesso em: 06 de novembro de 2018. 
MARRAS, Jean Pierre. Gestão de Pessoas em Empresas Inovadoras. São Paulo: Futura, 2005.

MELO, L.(30 de Outubro de 2017). Recessão brasileira acabou no fim de 2016, diz comitê da FGV que estuda ciclos econômicos. Fonte: G1. Disponível em: <https://g1.globo.com/economia/noticia/recessao-brasileira-acabou-no-fim-de-2016-dizcomite-da-fgv-que-estuda-ciclos-economicos.ghtml>. Acessado em: 07 de novembro de 2018.

MILKOVICH, George T.; BOUDREAU, John W. Administração de Recursos Humanos. São Paulo: Atlas, 2000.

MINAYO, M. C. S. (Org.). Pesquisa social: teoria, método e criatividade. Petrópolis: Vozes, 2001.

NONAKA, I. ; TAKEUCHI, H. Criação do conhecimento na empresa. Rio de Janeiro: Campus, 1997.

OLIVEIRA, A. P. Gestão do Conhecimento: estudo dos procedimentos da Gestão do Conhecimento em uma Universidade Pública. Pato Branco. Disponível em: <http://repositorio.roca.utfpr.edu.br/jspui/bitstream/1/919/1/PB_EGCF_VIII_2013_03.pdf>. Acessado em: 07 de Novembro de 2018.

OLIVEIRA, A.(18 de Janeiro de 2015). Cortar despesas em épocas de crise é uma decisão que requer critérios das empresas. Cruzeiro do Sul. Disponível em: <https://www2.jornalcruzeiro.com.br/materia/590161/cortar-despesas-em-epocas-de-crise-euma-decisao-que-requer-criterio-das-empresas>. Acessado em: 07 de novembro de 2018.

OLIVEIRA, M.; GOLDONI, V.; CONSTANTINO, F. Gestão do Conhecimento: pesquisas realizadas e novas oportunidades. In: ENCONTRO NACIONAL DE ENGENHARIA DE PRODUÇÃO, 26., 2006, Fortaleza. Anais, Fortaleza, ENEGEP, 2006.

OUTEIRO, E.T. Gestão de pessoas diante das crises econômicas. Porto Alegre, 2019. Disponível em: $<$ https://lume.ufrgs.br/bitstream/handle/10183/16787/000706271.pdf>.Acessado em: 07 de novembro de 2018. 
PEREIRA, Luciana. Entendendo a crise econômica mundial. Vol. 3, num. 6, 2013 Disponível

em:

<http://www.periodicoseletronicos.ufma.br/index.php/bauman/article/download/1959/3011>.

Acessado em 07 de novembro de 2018.

RODRIGUES, Luciana. Gestão do conhecimento: o grande desafio empresarial. Curitiba, 2010. Disponível em: <http://tcconline.utp.br/wp-content/uploads/2011/11/GESTAO-DOCONHECIMENTO-O-GRANDE-DESAFIO-EMPRESARIAL.pdf>. Acessado em 06 de novembro de 2018.

SALVADOR, J.A. Sociedade do Conhecimento: O que é e o que ela influencia? Disponível em: <http://www.mettodo.com.br/ebooks/Sociedade_do_Conhecimento.pdf>. Acessado em: 07 de novembro de 2018.

TERRA, J.C.C. Gestão do Conhecimento: o grande desafio empresarial. Rio de Janeiro: Campus, 2005.

TOFLER, Alvin. A terceira onda. 14. ed. Rio de Janeiro: Record, 1980.

VERGARA, Sylvia Constant. Projetos e relatórios de pesquisa em administração. 9 ed. São Paulo: Atlas, 2007. 


\section{Anexo}

Questionário sobre Gestão de conhecimentonas empresas

Questionário:

Me chamo Beatriz Góes Lacerda, estudo administração pela PUC-Rio, e estou fazendo o meu trabalho de conclusão de curso, e gostaria de contar com a sua ajuda para fazê-lo.

Prezado participante, este é um questionário que faz parte de um trabalho acadêmico de conclusão de curso de Administração, cujo tema é gestão do conhecimento. Seu objetivo principal é identificar de que forma a gestão do conhecimento minimiza os impactos da perda de conhecimento nas organizações, principalmente na crise brasileira, onde houveram vários cortes de funcionários.

Fico muito grata por sua colaboração, e reitero o compromisso de manter sigilo quanto as informações obtidas, elas serão utilizadas apenas para fazer uma análise sobre a gestão do conhecimento nas empresas em geral.

O que é gestão do conhecimento?

Para Davenport e Prusak, a gestão do conhecimento pode ser entendida como um conjunto de processos que visa a criação, disseminação e utilização do conhecimento para atingir os objetivos da organização.

(DAVENPORT \& PRUSAL,1998)

*Obrigatório

1. Nome da empresa em que trabalha: *

2. Seu cargo na empresa:

3. A empresa possui práticas que podem ser associadas à Gestão do conhecimento? * Marcar apenas uma oval.

Sim

Não

4. Se sim, existe uma área que tem a atribuição de fazer a Gestão do Conhecimento? Qual seria essa área? 
5. Quando a empresa começou a adotar a gestão do conhecimento aproximadamente?

6. A empresa enxerga a gestão do conhecimento como algo importante para o sucesso da empresa nos dias de hoje, onde o conhecimento tem papel preponderante nas decisões e atividades da organização?

Marcar apenas uma oval.

$\operatorname{Sim}$

Não

7. Quais vantagens enxergadas na gestão do conhecimento?

8. Como o conhecimento é gerado e codificado na empresa? (ex. capacitação de pessoas, contato com consultores e outras empresas, aquisição de colaboradores com o conhecimento desejado, etc.)

9. Como o conhecimento é disseminado na empresa?(ex. comunicação por meio de portais, repasse de conhecimento, mentoring, etc.) 
10. Como transforma o conhecimento tático (na cabeça das pessoas) em conhecimento explícito (sistematizado e de fácil consulta)?

11. Que ferramentas tecnológicas são utilizadas para facilitar a utilização do conhecimento? (ex. sistemas ERP, portais, soluções próprias, etc.)

12. A empresa realizou corte de funcionários recentemente?

Marcar apenas uma oval.

Sim, realizou cortes repentinos devido à crise econômica brasileira iniciada em 2014.

Sim, realizou cortes planejados devido a estratégias de negócio que culminaram na redução de pessoal.

Não realizou cortes de pessoal recentes.

13. Se sim, que critérios nortearam esses desligamentos? 
Custo de manter o funcionário

Natureza da atividade realizada por

ele Tempo na empresa

Grau de especialização

Conhecimento que ele possuía

Nível hierárquico

Outro:

14. A empresa considera que ao demitir algum funcionário, a empresa conseguiu manter o conhecimento deste funcionário dentro da empresa?

Marcar apenas uma oval.

Sim

Não 
15. Se sim, como os processos e ferramentas colaboraram para que acontecesse essa manutenção? Se não, o que poderia, em sua opinião, ser aperfeiçoado na gestão do conhecimento para impedir essa perda?

16. Em sua opinião, a gestão do conhecimento minimiza a perda de conhecimento na empresa? Se sim, de que forma? 